\title{
Review of the Selected Carbon-Based Materials for Symmetric Supercapacitor Application
}

\author{
MATEUSZ CISZEWSKI ${ }^{1,6}$ ANDRZEJ KOSZOREK, ${ }^{2}$ TOMASZ RADKO,${ }^{3}$ \\ PIOTR SZATKOWSKI, ${ }^{4}$ and DAWID JANAS ${ }^{5}$ \\ 1.-Department of Hydrometallurgy, Institute of Non-Ferrous Metals, Sowińskiego 5, 44-100 \\ Gliwice, Poland. 2.-Department of Inorganic Chemistry, Analytical Chemistry and \\ Electrochemistry, Silesian University of Technology, B. Krzywoustego 6, 44-100 Gliwice, \\ Poland. 3.-Institute for Chemical Processing of Coal, Zamkowa 1, 41-803 Zabrze, Poland. \\ 4.-Faculty of Materials Science and Ceramics, AGH University of Science and Technology, \\ Mickiewicza 30, 30-059 Kraków, Poland. 5.-Department of Organic Chemistry, Bioorganic \\ Chemistry and Biotechnology, Silesian University of Technology, B. Krzywoustego 4, 44-100 \\ Gliwice, Poland. 6.—e-mail: mateusz.ciszewski@imn.gliwice.pl
}

Carbon materials are among the most commonly used components of supercapacitor electrodes. Particularly, active carbons are recognized as cheap, available, and easily tailored materials. However, the carbon family, i.e. carbon products and carbon precursors, consists of many members. In this manuscript some of these materials, including laboratory scale-produced carbon gels, carbon nanotubes and carbonized materials, as well as industrial scale-produced graphites, pitches, coke and coal, were compared. Discussion was preceded by a short history of supercapacitors and review of each type of tested material, from early beginning to state-of-the-art. Morphology and structure of the materials were analyzed (specific surface area, pore volume and interlayer spacing determination), to evaluate their applicability in energy storage. Thermal analysis was used to determine the stability and purity. Finally, electrochemical evaluation using cyclic voltammetry, galvanostatic charge-discharge and electrochemical impedance spectroscopy was performed. Outcomes of each analytical technique were summarized in different sections.

Key words: Carbon, carbon gel, coal tar pitch, carbonized materials, energy storage, supercapacitors

\section{INTRODUCTION}

Electrical energy management is presently considered to be one of the main factors gauging the level of industrialization of a given country. Both its generation with possibly low environmental impact and its proper storage strongly influence the technological progress in each country all over the world. Electrical energy can be found in all important aspects of life, from a simple light bulb and small mobile devices improving the quality of life to

(Received July 10, 2018; accepted November 14, 2018; published online November 27, 2018) traffic lights, wastewater treatment plants, healthcare centres, markets, petrol stations and many others, which set the practical standard of citizen's subsistence level. Regarding the huge and rapidly growing demand on electrical energy, as well as over rational use of natural resources (oil, coal), the research has been focused on elaboration of more efficient energy storage solutions. Development of appropriate energy storage technologies would allow for reducing fossil fuel consumption and consequently the greenhouse effect. Better ways of storing electrical energy would also prevent power outages, which can be observed more frequently all over the world in recent years. ${ }^{1,2}$ Recently, the primary importance in energy storage is ascribed to 
lithium-ion batteries and supercapacitors. The main features of supercapacitors are the possibility of fast charging/discharging-quick delivery of huge energy portion in a short time, high power density, long cycle life, relatively simple construction from easily accessible materials, eco-friendliness (no disposal issues) and high coulombic efficiency (above 99\%), which means low amount of charge is lost in charge/discharge processes. ${ }^{3}$

The predecessors of currently used energy storage materials were the Leyden jar and Voltaic pile. ${ }^{4}$ Capacitors can be generally divided into three classes of devices: electrostatic, electrolytic and electrochemical capacitors. The electrostatic are composed of two metal electrodes separated by dielectric. Similarly, electrolytic capacitors have metal electrodes; however, an electrolyte is a conductive salt, while electrochemical capacitors have an aqueous electrolyte with porous electrode materials. $^{5}$

The history of supercapacitors in the present form dates back to 1957, when the engineer of General Electric, Howard Becker, constructed a device of this type and submitted a patent concerning it. ${ }^{6}$ This initial step was in fact not considered very important in those days. Nevertheless, the interest in supercapacitors grew, since the SOHIO (Standard Oil of Ohio) company constructed in the mid1960s a carbon-carbon electrochemical capacitor. ${ }^{7,8}$ The new technology was in fact marketed in the 1970s by the NEC (Nippon Electric Company), which used supercapacitors to serve as a backup power device for computer memory applications. ${ }^{9,10}$ Until the 1980s, supercapacitors were based on simple electric charge separation between the electrode material and electrolyte. Then the first pseudocapacitors were developed, in which electric charge was partially stored in a double layer and partially came from the result of faradaic reactions of electrolyte and electrode. ${ }^{11}$

Regarding constructional and working factors three groups of supercapacitors can be distinguished: electrochemical double-layer capacitors, pseudocapacitors and hybrid capacitors. Quite often the terms hybrid and asymmetric supercapacitors are confused. The hybrid supercapacitors are composed of two different electrodes, one governed by electrostatics and one by electrochemical principle, while asymmetric electrodes have one typical EDLC (electric double-layer capacitor) electrode and one composite electrode of porous carbon with metal oxide or conductive polymer. ${ }^{12}$ At the same time, two terms are used to define these specific classes of materials, namely, supercapacitors, the term coined by the NEC, and ultracapacitors used by PRI (Pinnacle Research Institute). ${ }^{5}$

The principle of supercapacitor operation is based on charge separation between two porous electrodes. The key rule is the formation of a double layer at the electrode/electrolyte interphase, which can be described using three models. The first was proposed by Helmholtz, ${ }^{13}$ and assumes diffusion of opposite ions through an electrolyte and formation of a few nanometer-thick layer at the electrode, called the electrical double layer. ${ }^{14}$ Inaccuracies of this model were corrected by the Gouy-Chapman diffusion model. ${ }^{15,16} \mathrm{~A}$ model proposed by Stern in $1924,{ }^{17}$ that combines assumptions of Helmholtz, Gouy and Chapman, considers formation of an interphase composed of ions and a solvation shell. ${ }^{18}$ It was also found that in the case of ionic liquid electrolytes, partial ion desolvation must occur to allow ions to access the pore. ${ }^{19}$

Well-described and precise analysis of the movement of electrolyte ions within the pores during the charging process was presented by Forse et al. ${ }^{20}$ They proposed three possible routes: adsorption of oppositely charged (counter) ions, adsorption of oppositely charged ions with simultaneous desorption of co-ions, and desorption of co-ions only, which is a consequence of presence of some initial electrolyte ions before applying voltage.

Because of the versatility of applications, supercapacitors can be used in cell phones, laptops, audio-video systems, security and alarm systems, smoke detectors, as well as elevators, lifts, cranes-which are normally not able to recuperate energy. ${ }^{21,22}$ It is common to integrate them in uninterruptible power supply systems. ${ }^{23}$ An important branch is the automotive industry in small cars, heavy trucks, buses, trams and trains, in which supercapacitors are responsible for engine start, vehicle acceleration, windows and back-door lift. $^{24,25}$ Supercapacitors are important in a cold start, when at very low temperature the high viscosity of lubricating oil prevents the system from ignition. $^{26,27}$

The requirements that should be met by a promising electrode material are electrical conductivity, chemical inertness, gas or liquid adsorption permission, relatively high surface area, and state of material, whether it is powder, fiber or monolith. For this reason, active carbons and modified graphites are most commonly used. On the other hand, high ion conductivity, low price and possibly wide-voltage-window electrolytes are required. The conductivity (ca $1 \mathrm{~S} / \mathrm{m}$ ) and low price make aqueous electrolytes ideal for supercapacitors. The drawback is a voltage window limited to $1.2 \mathrm{~V}$ (water decomposition). ${ }^{28}$ Wider stability range can be found for organic electrolytes $(2-2.5 \mathrm{~V})$; however, safety risks concerning flammability, volatility and toxicity are troublesome. ${ }^{29}$ The $\sim 4 \mathrm{~V}$ voltage window can be offered by ionic liquid,s but still this technology is relatively expensive and complex for industrial applications. ${ }^{30,31}$

The specific surface area of electrode material is a key parameter; however, one should remember the general trend: a bigger surface area does not always translate into higher specific capacity. ${ }^{32}$ It also seems important to have appropriate porosity within material with macropore channels to 
transport electrolyte and micropores to store ions. In fact, too large of a pore volume may limit high power and energy density, while too small pores may be impossible to be penetrated by electrolyte ions. ${ }^{33,34}$ Commonly, carbon materials are activated with potassium hydroxide or carbon dioxide to open clogged pores. ${ }^{35}$ Presence of the functional groups can play a significant role in electrode performance as well. ${ }^{36,37}$

Large versatility of the carbon-based materials family makes them ideal for tailored materials preparation. Graphite, which exhibits high electrical and thermal conductivity, inertness and lubricity, is among the most often used candidates for this purpose. Two basal form of graphite can be found, synthetic, with a hexagonal structure and $A B A B A B$ layers order, and natural, with a mixture of rhombohedral and hexagonal structures and an ABCABC layer sequence. ${ }^{38,39}$ Synthetic graphite is obtained in unstructured carbon thermal treatment in Acheson, Castner or Desulco processes, ${ }^{40-42}$ while natural graphite, either macrocrystalline or microcrystalline (flake and vein), is mined in Sri Lanka, China, Brasil, Canada and Russia. ${ }^{43,44}$ To increase the specific surface area, the graphite flakes can be intercalated by the oxygen-containing groups and thermally treated at high temperature (thermal shock) to produce expanded graphite, which is used in battery applications. ${ }^{45,46}$

Furthermore, cokes can be classified into three groups based on feedstock used for their production: petroleum coke, metallurgical coke and pitch coke. Petroleum coke is the heaviest product of fractional distillation of crude oil, metallurgical coke is produced primarily from coal, while pitch coke is a solid residue from devolatilization and carbonization of tars and pitches. ${ }^{47}$ Based on coking process parameters and crude oil quality, different structures of petroleum coke can be obtained-needle coke (anisotropic, low sulfur content), sponge coke (porous), and the shot coke (isotropic, granular). ${ }^{48}$

Next, one could consider pitches, which can be divided into two groups based on the type of starting material, i.e. coal tar pitch and petroleum pitch. Coal tar pitch is a product of coal tar processing at coal plants, while petroleum pitch is produced from oil-processing byproducts, thermal and catalytic cracking residues. Pitches are used as binders in mass production of graphite electrodes. ${ }^{49}$

Activated carbons are an important class of carbon materials, which have high degree of porosity and well-developed surface area. They can be produced from natural organic materials succh as fruit stones and peels, wood and agricultural waste. $^{50,51}$ Because of the abundant supply, high purity and environmental advantage with respect to coal-based carbons, the activated carbons produced from coconut shells have recently received growing attention. ${ }^{52}$

Carbon nanostructures such as graphene, carbon nanotubes and fullerenes seem to be the future perspective of energy storage materials. Pure fullerenes are electrically insulating, and their synthesis is strongly complicated at a bigger scale. $^{53,54}$ Both monolayer graphene and singlewalled carbon nanotubes are attractive, but due to the requirement of complex and expensive apparatus for their production, their real life applications have been limited so far. ${ }^{55}$ An alternative is to use reduced graphene oxide, which can be obtained using chemical reduction of graphene oxide. ${ }^{56}$

Furthermore, mild and slow pyrolysis, at around $200-300^{\circ} \mathrm{C}$, of the carbon-bearing natural resources such as biomass, wood or straw can be used to produce intriguing torrefied materials, while at higher temperatures carbonized materials are produced, which can be successfully used in various applications. $^{57}$

Lastly, carbon gels are a novel group of carbon materials that can be considered for energy storage applications. Regarding the drying method used, i.e. supercritical drying, freeze drying or ambient pressure drying, different products can be obtained including aerogels, cryogels, and xerogels, respectively. For instance, the gelation process of resorcinol and formaldehyde can be performed under alkaline or acid conditions. $^{58}$

Generally, the global market of supercapacitors was estimated to USD $\$ 115 \mathrm{M}$ in 1999 , and it was predicted in those days that it may be doubled in $2004 .{ }^{59}$ Estimations in 2010 indicated that the market would amount to USD $\$ 470 \mathrm{M}$, USD $\$ 1.2 \mathrm{~B}$ in 2015 , and would eventually reach USD $\$ 5 B$ in 2025 . $^{60}$ Supercapacitors are manufactured inter alia by APowerCap, Asahi Glass, BatScap, Chubu Electric PowerEpcos, Fuji, Ioxus, JSR Micro, LS Mtron, Maxwell, NessCap, Panasonic, PowerStor, SAFT, Skeleton, VinaTech, Yunasko. ${ }^{61}$

\section{Active Carbons and Carbonized Materials}

Active carbon is a highly porous and high surface area material with a disordered microcrystalline structure. Its production combines carbonization of a raw carbon precursor at temperatures below $800^{\circ} \mathrm{C}$ in an inert atmosphere and chemical or physical activation of an as-obtained semi-product. ${ }^{62-64}$ The popular raw materials include coal with a various degree of metamorphosis (both low and high degrees of coalification, ${ }^{65}$ brown coal, ${ }^{66}$ peat, ${ }^{67}$ charcoal, ${ }^{68}$ seeds of fruits, nut shells and other lignocellulose materials $\left.{ }^{69-77}\right)$, as well as industrial waste ${ }^{78}$ waste from the agri-food industry, ${ }^{79-83}$ sewage residues, ${ }^{84-88}$ waste tyres ${ }^{89-91}$ and plastic waste. ${ }^{92-94}$ Pyrolysis results in elimination of oxygen, hydrogen and nitrogen atoms. The remaining carbon forms a complex structure composed of "piles" of aromatic rings randomly cross-linked throughout the material. At the end of carbonization, the produced pores are partially filled with pyrolysis products of the organic matter (mainly tarlike substance and amorphous carbon). Quality of 


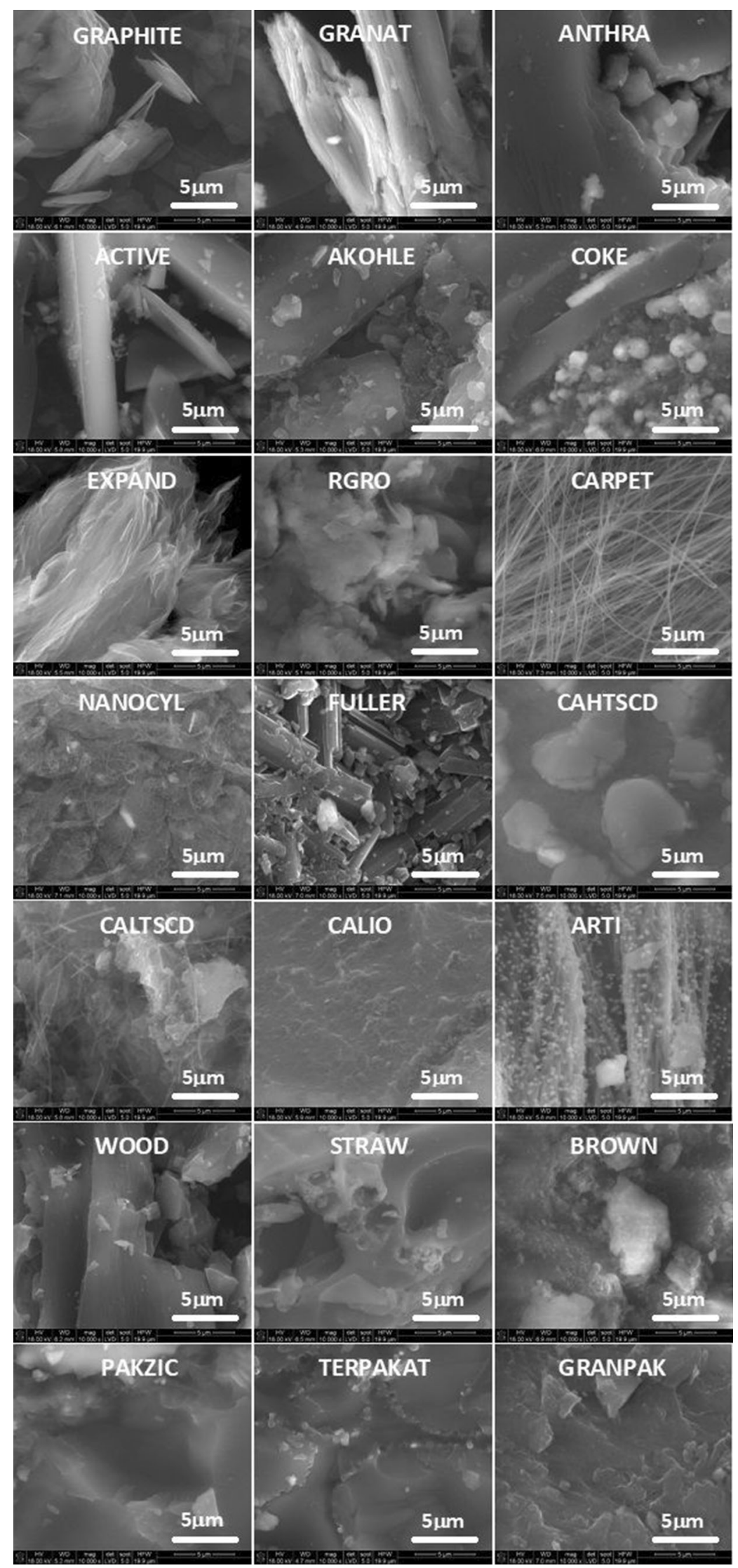

Fig. 1. SEM images of tested materials at magnification $\times 10000$. 


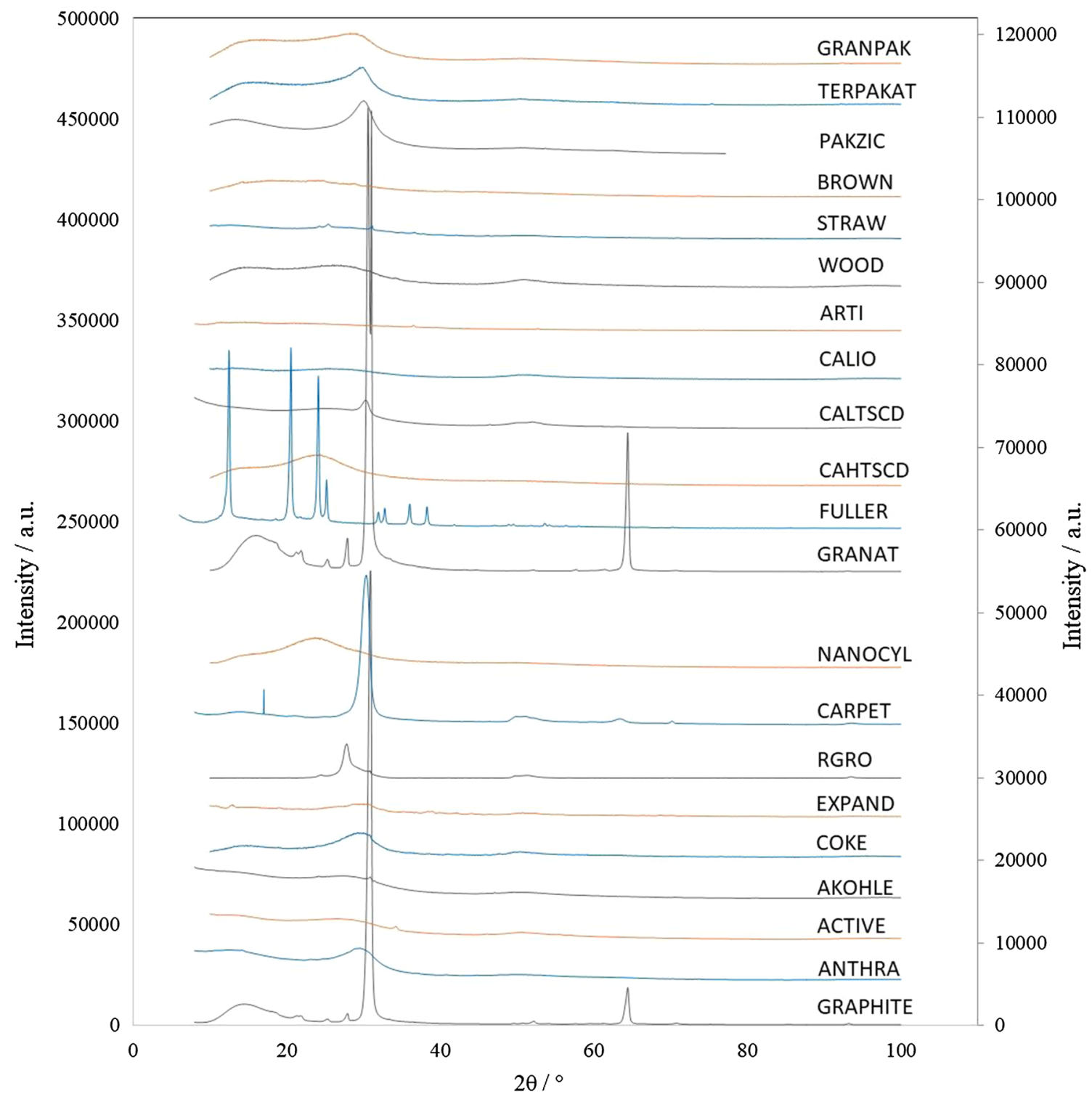

Fig. 2. XRD patterns of examined materials.

the product depends on the final process temperature (key factor, the higher temperature, the lower reactivity of carbonized material), time of carbonization, heating rate (affecting the reactivity), pore sizes, and type of atmosphere at which the process is performed (which affects the reactivity and rate of loss of carbonized material). ${ }^{63,64}$ Because of poorly developed pore structure, the as-prepared material has a low adsorption capacity. ${ }^{63,95}$ For this reason activation is used to develop structure and purify it from pyrolysis products. This can be performed using gas-vapor or chemical methods. During gasvapor activation $\left(750-950^{\circ} \mathrm{C}\right)$ the structure of carbonized material is partially oxidized at elevated temperature using gaseous atmosphere: oxygen, water vapor, carbon dioxide (in an order of the oxidizing agent reactivity). Using a milder activating agent, more developed structure can be obtained. Activation is a strongly temperature-dependent process. Reaction is catalyzed by oxides and carbonates of alkali metals, iron, copper and zinc. ${ }^{96}$ Chemical activation refers to materials processing in oxidizing acids $\left(\mathrm{HNO}_{3}, \mathrm{H}_{2} \mathrm{SO}_{4}, \mathrm{H}_{3} \mathrm{PO}_{4}\right)$ or salts solutions $\left(\mathrm{ZnCl}_{2}, \mathrm{MgCl}_{2}, \mathrm{FeCl}_{3}, \mathrm{AlCl}_{3}, \mathrm{~K}_{2} \mathrm{~S}\right)$. In comparison to gas-vapor activation, the chemical activation produces more uniform pore sizes. ${ }^{64,97}$ Finally, active carbon with a well-developed polydispersive porous structure with high surface area close to $2500 \mathrm{~m}^{2} / \mathrm{g}$ is formed. The various size and shape of pores within spatial structure of materials is obtained. According to the International Union of Pure and Applied Chemistry (IUPAC), these pores can be classified into three groups: micropores with a pore diameter smaller than $2 \mathrm{~nm}$, mesopores with diameter 2-50 $\mathrm{nm}$ and macropores of sizes bigger than $50 \mathrm{~nm} \cdot{ }^{98}$ Generally, the micropore content is 

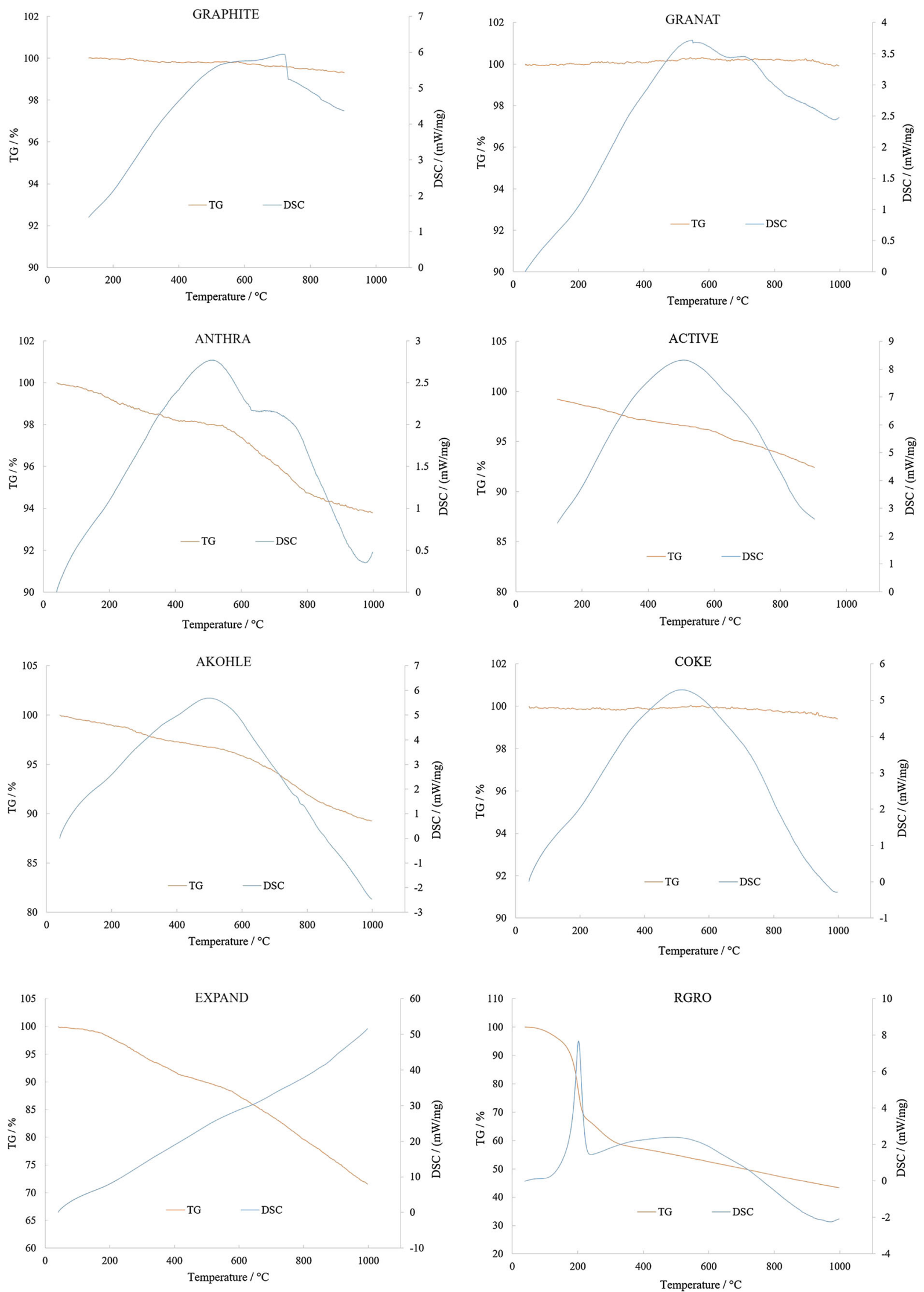

Fig. 3. TG and DSC curves for carbon-based materials. 

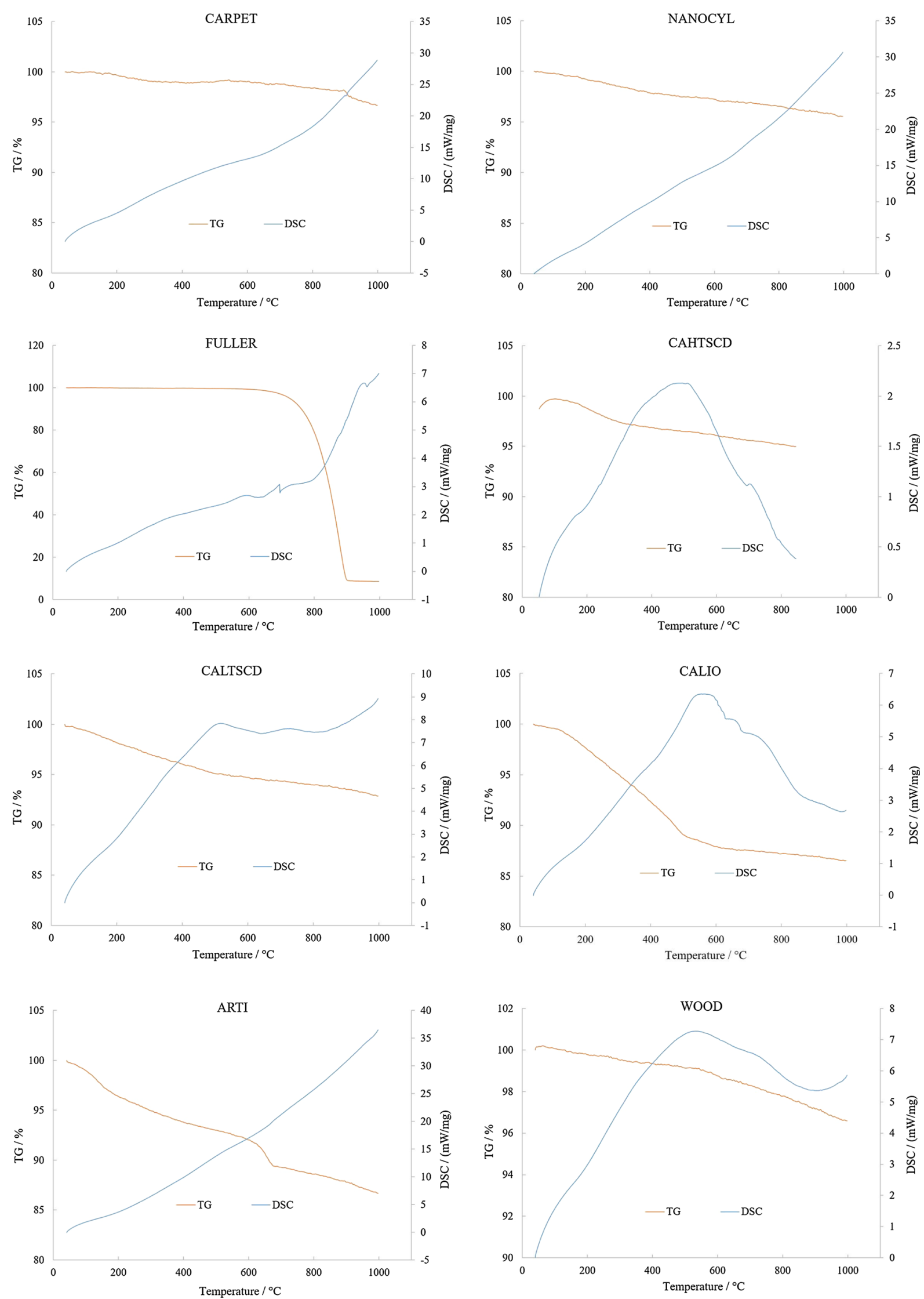

Fig. 3. continued. 

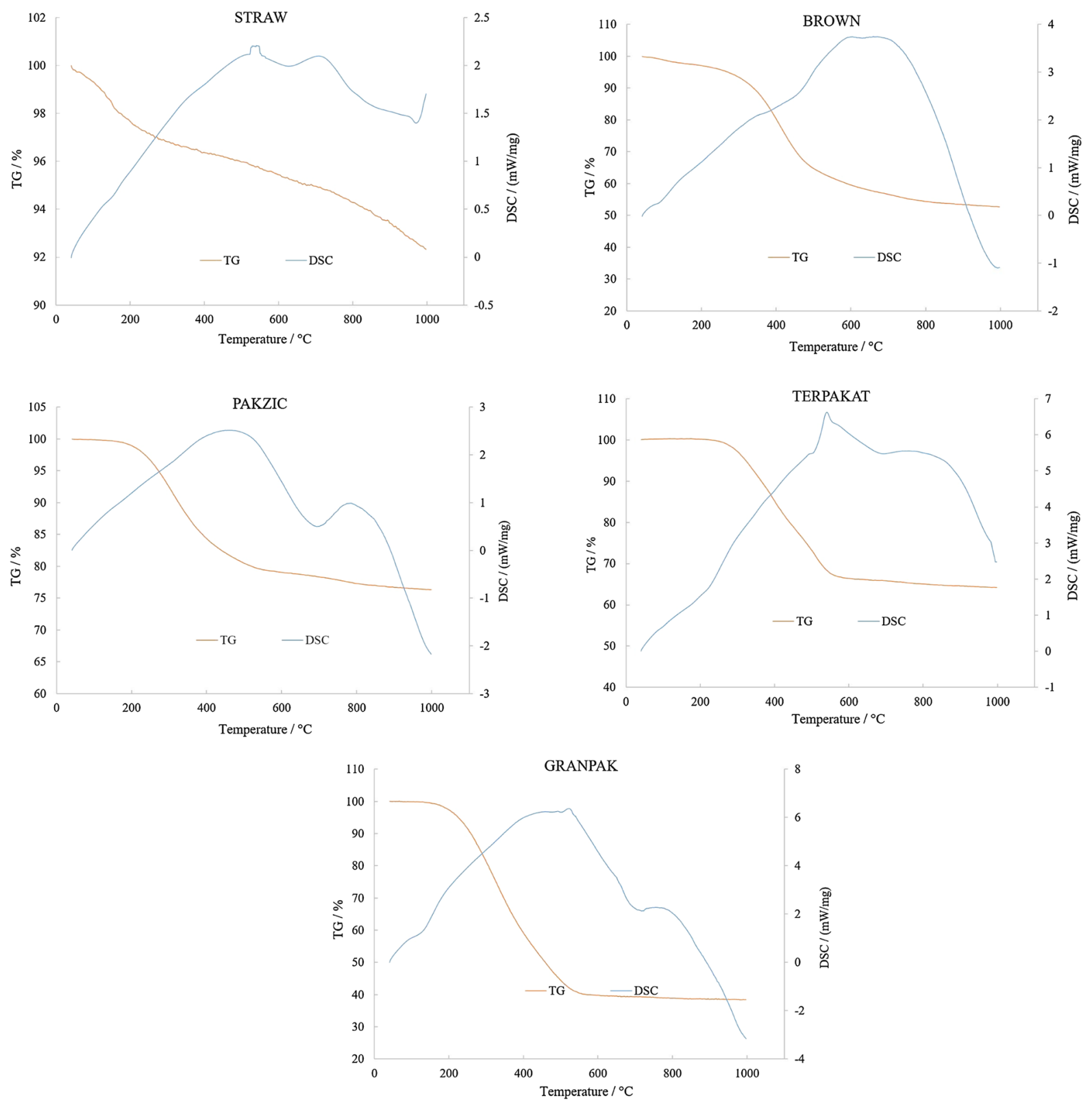

Fig. 3. continued.

95\% of the total surface area, 5\% is attributed to mesopores and the rest is the area of macropores. Active carbons may have some amount of oxygen, hydrogen and nitrogen atoms within the pores (the typical elemental composition of active carbon: 88 wt.\% C, 6-7 wt.\% O, 1.0 wt.\% S, 0.5 wt.\% H, 0.5 wt. $\% \mathrm{~N}$ and Ref. 63) that may render their properties. For example, presence of the oxygencontaining groups is important, which may enhance wettability, polarity and basicity (acidity) of material, and electronic properties.

Regarding extraordinary properties of active carbons, namely, high surface area per either volume or mass unit and relatively low production costs and global output scale, they are thought to be the most suitable electrode materials for electrochemical capacitors. High specific surface area enables storing a much bigger amount of charge in the electric double-layer at the phase boundary than is observed for other carbon materials. ${ }^{14,99-103}$

\section{Graphene}

Even though the isolation of 2-D carbon material was thought by many scientists to be nonrealistic for a long time, ${ }^{104,105}$ the first attempt in this matter was successfully accomplished by Wallace in 1947. ${ }^{106}$ Then in 1962 the first trial of graphite oxidation and reduction were performed by Boehm. ${ }^{107}$ This led to the conclusion that graphene layers can be chemically separated; however, their total isolation was still a challenge. It was not until 

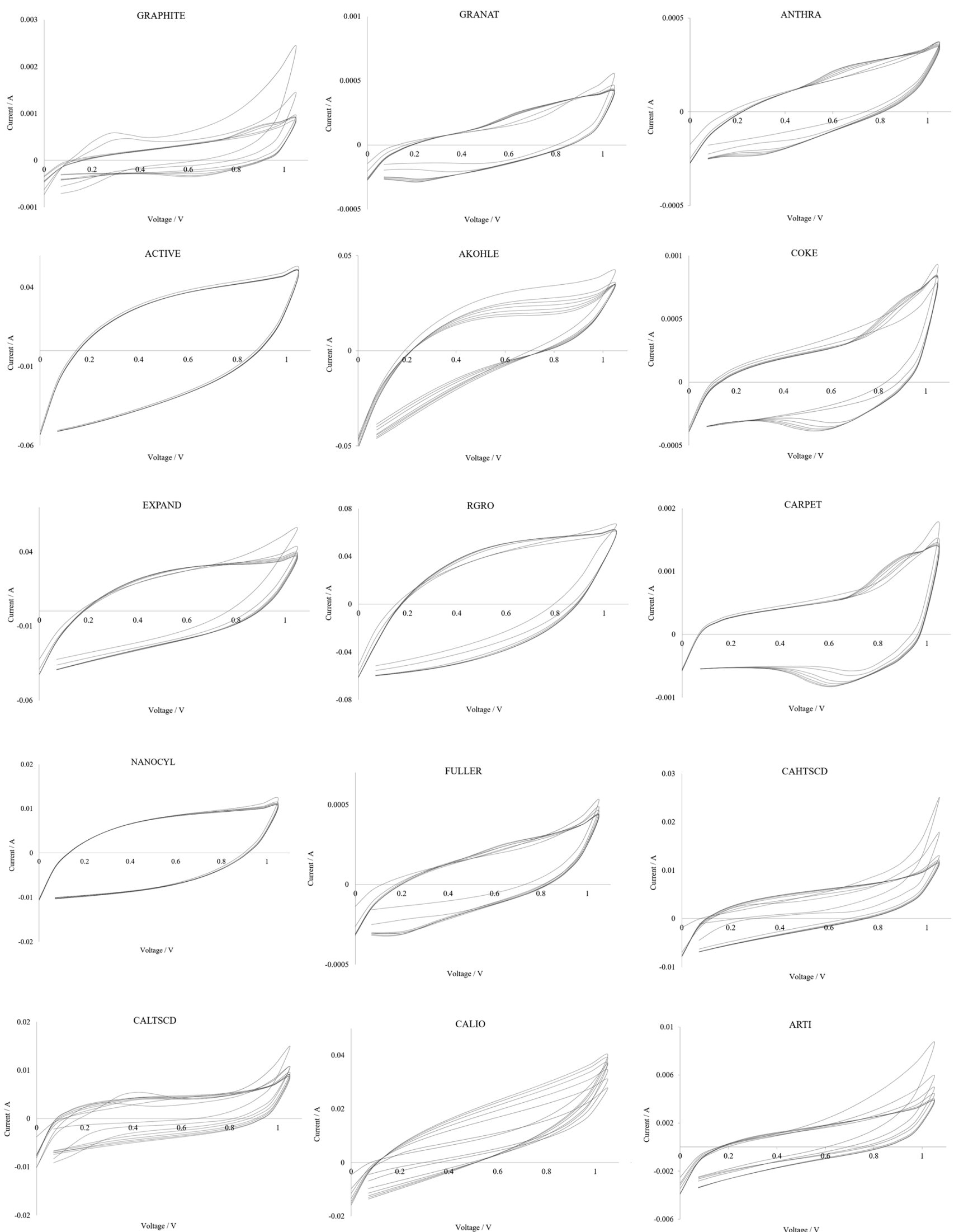

Fig. 4. CV curves registered in 1000 charge/discharge cycles.

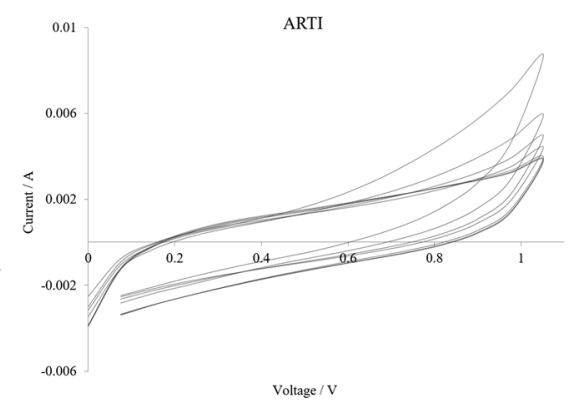



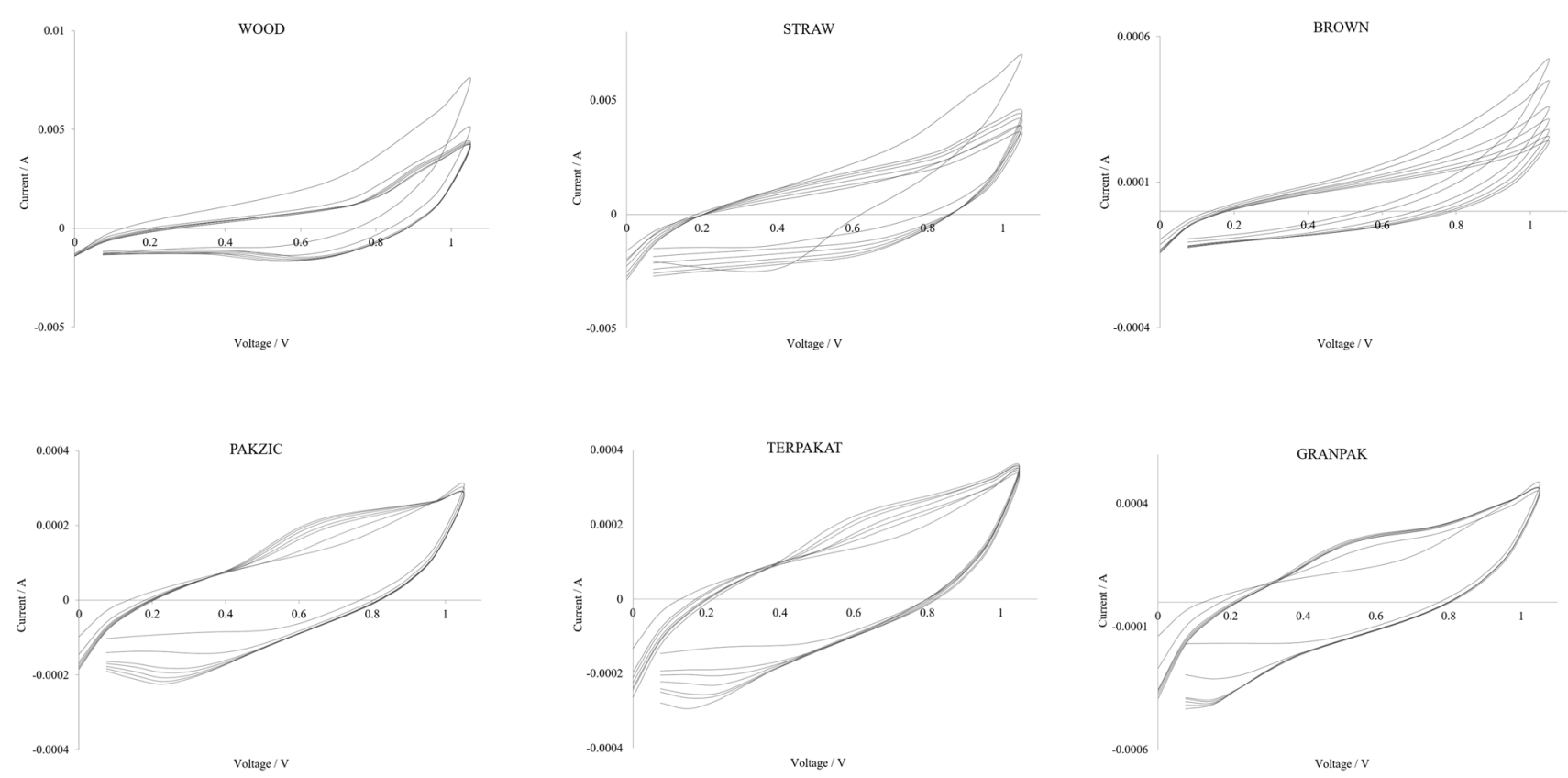

Fig. 4. continued.

2004 that the first success on this front was done $\mathrm{e}^{108}$ using a very simple method of microchemical cleavage. The process, which is also known as the Scotch tape method, and the characterization of a new material led the discoverers to the Nobel Prize in Physics in 2010. Nowadays, mechanical cleavage is best suited for laboratory research of graphene, while newer methods were invented to produce this fascinating material in bigger amounts. One of such techniques is the chemical exfoliation of graphite in organic solvents, which penetrate the interlayer spacing of graphite and consequently weaken the van der Waals forces holding the layers together. ${ }^{109}$ The process is often assisted by mechanical agitation. A historically important route is based on graphite oxidation and reduction. In this method, graphite is at first treated with a mixture of a concentrated inorganic acid and a strong oxidation agent, usually according to the methodologies proposed by Brodie, Staudenmaier and Hummers. ${ }^{110-112}$ This produces graphite oxide with oxygen-containing groups embedded between layers. According to the model proposed by Lerf and Klinowski, in graphite oxide the hydroxyl and epoxy groups are located between layers, whereas carboxylic groups can be found at the edges. ${ }^{113}$ In the subsequent step, graphite oxide is ultrasonicated into graphene oxide. This opens the interlayer spaces and makes it easily accessible for the reducing agent. Exfoliated graphene oxide is then reduced by chemical agents, e.g. hydrazine, ${ }^{114}$ metal hydrides, ${ }^{115}$ metals, ${ }^{116}$ vitamin $C .{ }^{117}$ In the past, the as-obtained product was referred to as graphene. Nowadays, it is accepted to use term reduced graphene oxide to differentiate it from flat graphene layers obtained by more sophisticated techniques.
Graphite oxide can be simply exfoliated using thermal treatment at about $1000^{\circ} \mathrm{C},{ }^{118}$ but neither chemical nor thermal methods are able to remove the oxygen species entirely. To accomplish graphite oxide or graphene oxide reduction, the flash of a camera $^{119}$ or UV irradiation ${ }^{120}$ can be applied as well. Oxidation and reduction seems to be a perfect method to produce a large volume of graphene, but one should recall its imperfection. On the contrary, epitaxial growth is an effective method to produce high-quality graphene from a silicon carbide substrate. The SiC wafer is heated in ultra high vacuum around $1200-1600^{\circ} \mathrm{C}$, silicon atoms sublime while carbon atoms rearrange creating flat graphene layer. ${ }^{121,122}$ Similarly, large and flat graphene sheets can be obtained by chemical vapor deposition, which is based on pyrolysis of hydrocarbons wherein graphene grows on transition metals. ${ }^{123}$ Regarding the solubility of carbon atoms in certain transition metals either mono, few or multilayer graphene can be obtained. The quality of product from both CVD and epitaxy based methods is very high, which is reflected in the price of these materials obtained by these methods. Graphene has been widely studied as a promising candidate in various applications including electronic, optoelectronic and sensing devices. It can be found in energy storage applications like supercapacitors or lithiumion batteries, ${ }^{124}$ field effect transistors, ${ }^{125}$ solar cells ${ }^{126}$ and catalysis. ${ }^{127}$

\section{Carbon Nanotubes and Bucky-Balls}

Although carbon nanotubes (CNTs) were discovered in the $1950 \mathrm{~s},{ }^{128}$ they were largely unnoticed until the very influential report from Iijima made them popular. ${ }^{129}$ The properties of CNTs, often 

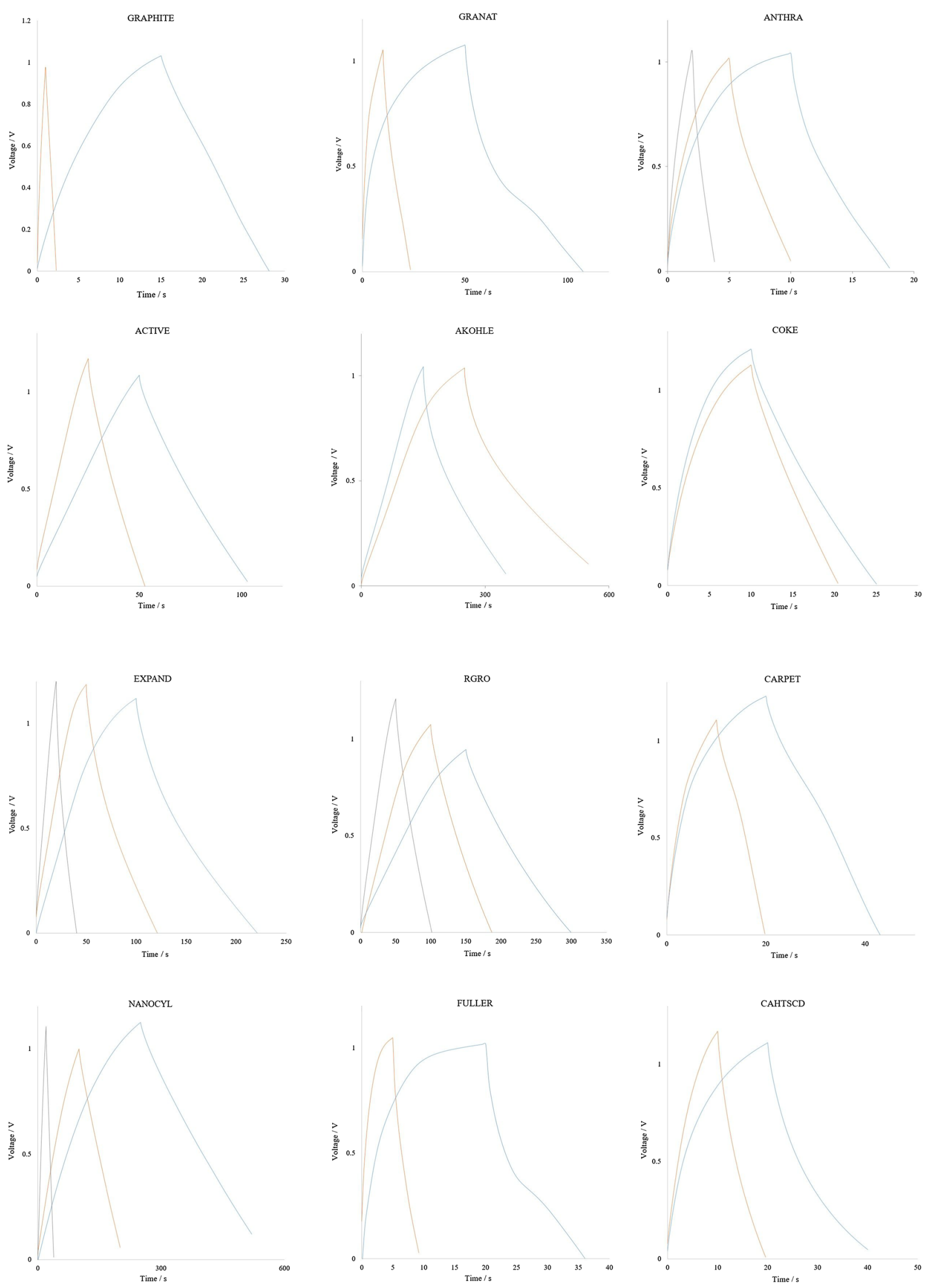

Fig. 5. Chronopotentiometric results obtained for various carbon-bearing materials. 

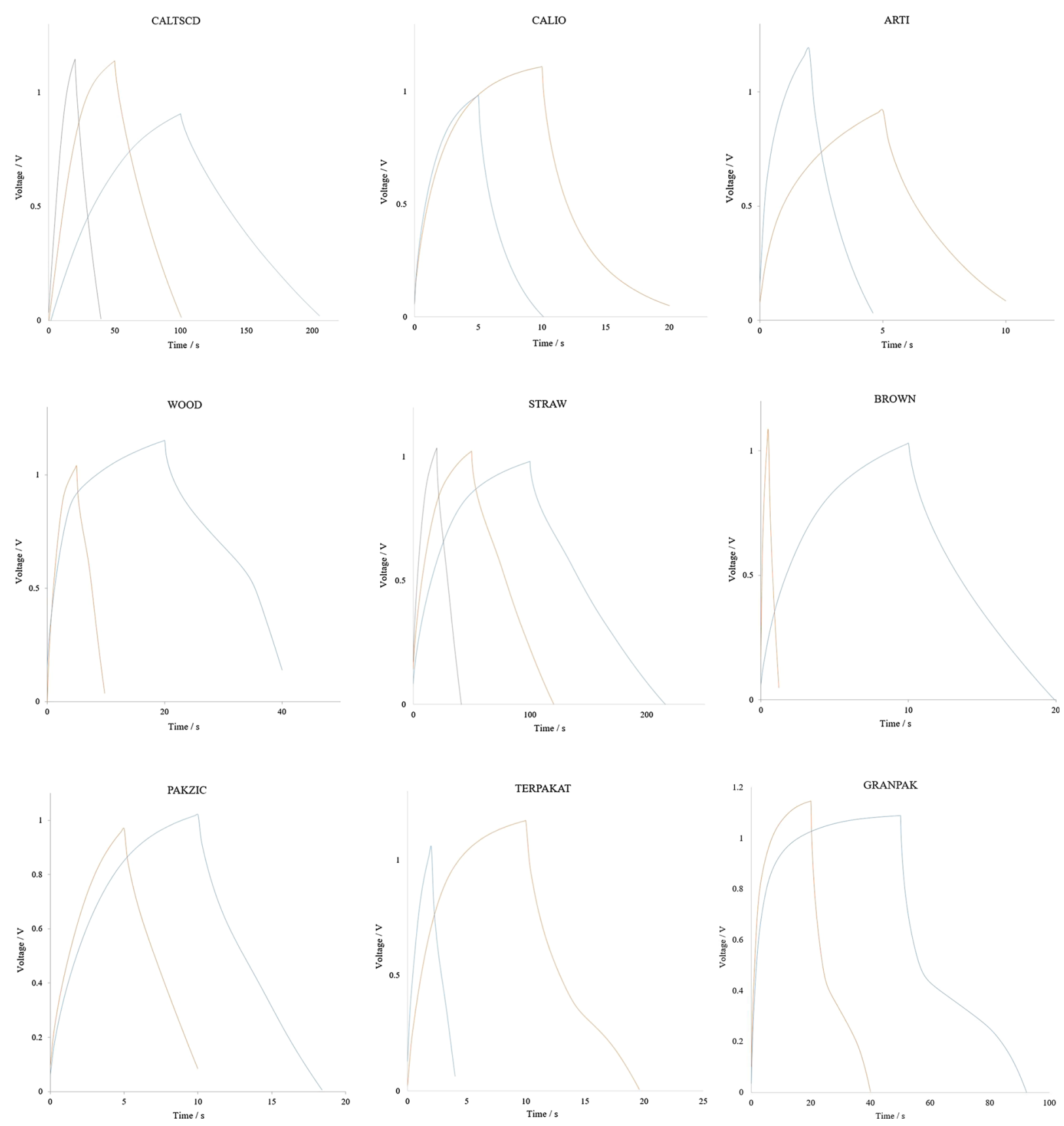

Fig. 5. continued.

imagined as seamlessly rolled-up graphene with individual (single-walled CNTs) or many concentric layers (double-walled and multi-walled CNTs), are very sensitive to the way that roll-up was accomplished. For instance, depending on the arrangement of carbon atoms, CNTs can either show metallic character and compete with copper in terms of electrical conductivity ${ }^{130}$ or they are semiconducting, and their performance is superior to that of silicon. ${ }^{131}$ Individual CNTs of appropriate order of carbon atoms called chirality can have three orders of magnitude higher current carrying capacity $^{130}$ and one order of magnitude higher thermal conductivity ${ }^{132}$ than copper. For this reason they have been envisioned as the next generation lightweight flexible wiring of improved performance ${ }^{133-136}$ or heat sinks. ${ }^{137}$ The first electrical machines based on such wiring have already been constructed. ${ }^{138}$ CNTs are also among the strongest materials on Earth, with Young's modulus reaching $950 \mathrm{GPa}$ and tensile strength up to 63 GPa. ${ }^{139}$ There has been a lot of development of polymer-matrix composites reinforced with CNTs that not only drastically improve the mechanical properties, ${ }^{140,141}$ but they also provide means for current conduction, which, for example, is very 

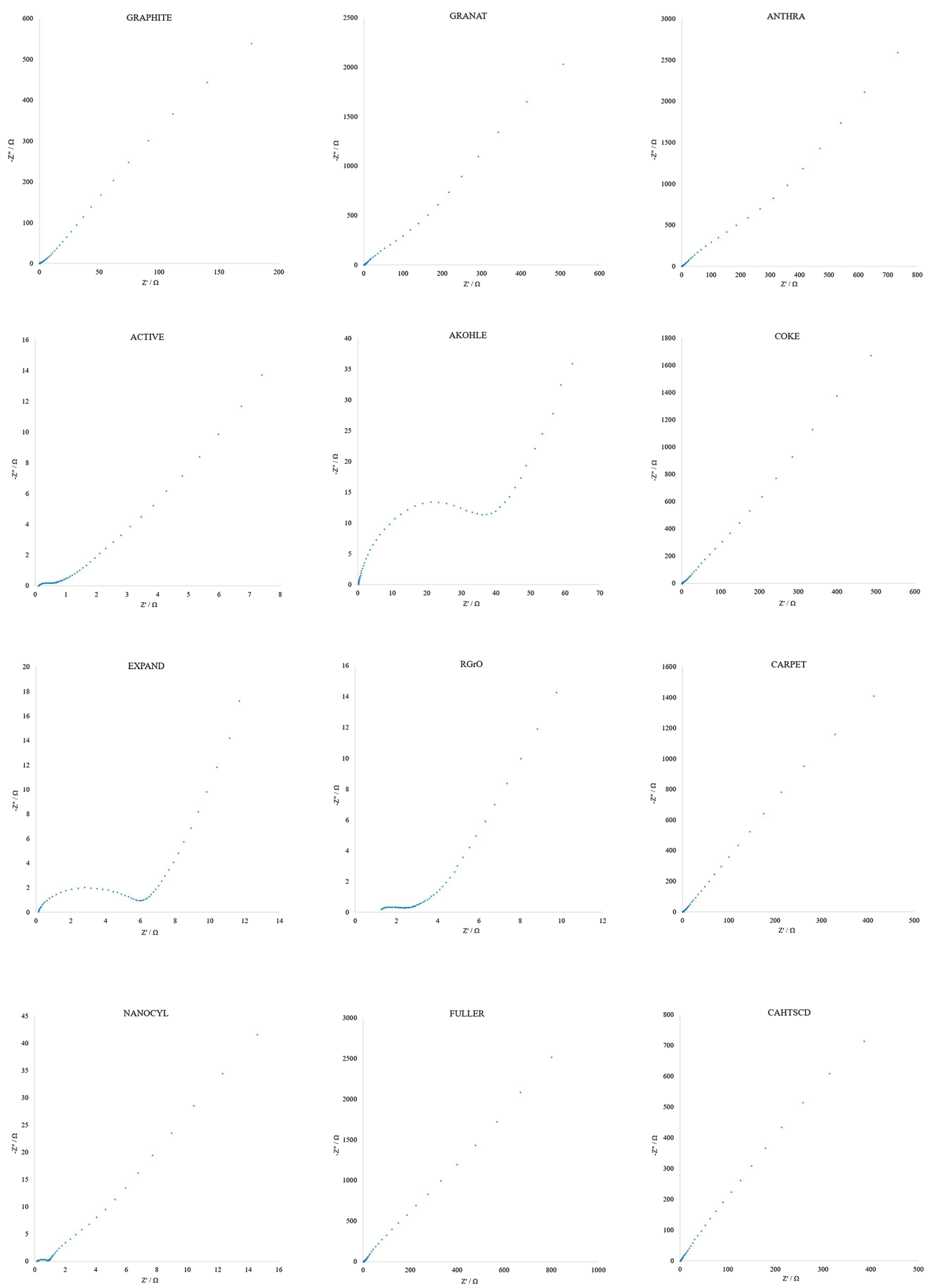

Fig. 6. Nyquist plots obtained for the analyzed materials. 

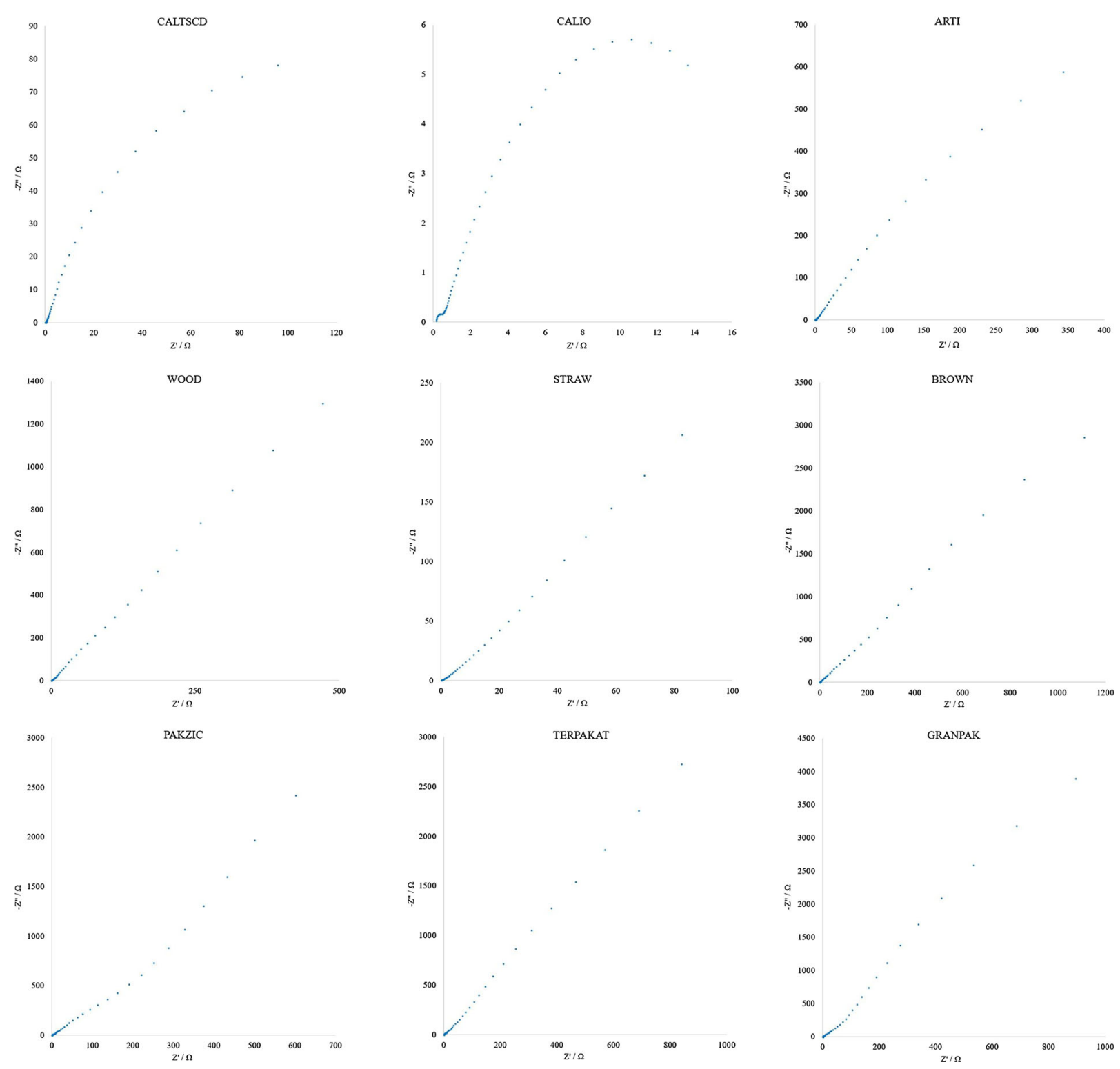

Fig. 6. continued.

important in composites used for aircraft lightning protection. ${ }^{142}$ Finally, the rich spectral response of CNTs makes them a very attractive material for various optoelectronic applications. ${ }^{143}$ By applying appropriate bias voltage, one can observe surprisingly strong light emission that does not follow black body radiation, the character of which can be precisely controlled by the type used CNTs. ${ }^{144}$ Regarding the applications, CNT composites were commercially used in a bicycle winning Tour de France, CNT paint was employed to cover a ship hull for antifouling action or Juno spacecraft had CNT layer as a shield material from electrostatic discharge. ${ }^{145}$ Continuous significant reduction in price of CNT powder (both single-walled and multiwalled) will eventually lead to more abundant presence of these materials in the everyday life.
CNTs can be considered quasi-1D materials. When their length is reduced to minimum, the spherical fullerenes, called bucky-balls of quasi-0D nature, are obtained. The name bucky-ball in fact is a reference to Buckminster Fuller, who created a geodesic dome of a similar shape prior to the discovery. These structures are commonly made of 60 carbon atoms, which are arranged in a pentagonal and hexagonal lattice similar to a football ball. The structure was first generated in $1985^{146}$ by Kroto, Curl, Smalley et al., ${ }^{147}$ for which the trio later received the Nobel Prize in Chemistry in 1996. Such material is semiconducting although the band gap is as low as $0.1-0.3 \mathrm{eV}$. Because the inner cavity is relatively big, bucky-balls can readily accommodate ions inside such as alkali metals ${ }^{148}$ or iodine. ${ }^{149}$ The presence of such species can have a very strong doping action on $\mathrm{C}_{60}$, which is able to transform it 
into a conductor or even a superconductor. ${ }^{150,151}$ For example, K-doped C60 can preserve its superconducting character at a relatively high temperature of $18 \mathrm{~K}^{152}$ Furthermore, a high C-C bond strain makes this molecule reactive towards various functionalization methods, which creates new forms of bucky-balls. This structure can readily be hydrogenated, ${ }^{153}$ halogenated, ${ }^{154}$ oxidized, ${ }^{155}$ etc. Unfortunately, no applications of $\mathrm{C}_{60}$ have been commercialized yet.

\section{Carbon Gels}

The inorganic aerogels have been known since $1931,{ }^{156}$ while their carbon counterparts were first synthesized by Pekala in $1989 .{ }^{157}$ Carbon gels are a new class of materials, which are characterized by high surface area, low weight and tunable properties. Synthesis is mostly based on polycondensation of resorcinol and formaldehyde under basic or acidic conditions. The production is generally composed of several stages: gelation, aging, solvent exchange, drying and pyrolysis. In the gelation step resorcinol derivatives condense through $-\mathrm{CH}_{2}$ - bridges into bigger clusters and cross-links through $\mathrm{CH}_{2} \mathrm{OH}$ groups into gel. ${ }^{158}$ The process is strongly influenced by $\mathrm{pH}$. Acidic or basic catalysts are responsible for either condensation or an addition reactionbased mechanism. ${ }^{159}$ Catalyst amount, often referred to $\mathrm{R} / \mathrm{C}$ (resorcinol/catalyst) ratio, is also very important, as at low $\mathrm{R} / \mathrm{C}$ well-connected small particles are obtained while at high well-defined spherical particles are produced. ${ }^{160}$ It is assumed that the most favorable results can be obtained at $\mathrm{pH}$ in the range $5-8 .{ }^{161}$ With the exception of resorcinol, other monomers such as phenol, cresols, gallic acid or phloroglucinol have been proposed and examined. ${ }^{162}$ Aging is realized at an increased temperature of $60-80^{\circ} \mathrm{C}$, which is required for the polymerization reaction. Generally, the higher is temperature of aging the shorter time is needed to accomplish this process; however, this may lead to smaller particles and reduced pore size distribution. ${ }^{163}$ Next the parent solvent has to be extracted from pores using low boiling point and low surface tension solvent such as acetone. The goal of this simple and relatively crucial step is to reduce shrinkage of material during drying. ${ }^{164}$ The most complex step in carbon gels synthesis is drying. Three techniques are usually applied: supercritical drying, freeze drying (liofilization) and ambient drying and the obtained products are carbon aerogels, cryogels and xerogels, respectively. Supercritical drying can be done in two variants, lowtemperature supercritical drying (LTSCD) and high-temperature supercritical drying (HTSCD). In LTSCD, carbon dioxide above its critical parameters is used $\left(T_{\mathrm{C}}=31^{\circ} \mathrm{C}, p_{\mathrm{C}}=7.4 \mathrm{MPa}\right)^{165}$ is used, while in HTSCD, an organic solvent such as acetone or methanol is preferred (acetone $T_{\mathrm{C}}=235^{\circ} \mathrm{C}, p_{\mathrm{C}}=$ $4.7 \mathrm{MPa}){ }^{166}$ Freeze drying is based on solvent freezing within the pores and its subsequent sublimation. Prior to freezing, the solvent is exchanged into t-butanol because of its very small volume change with respect to freezing. ${ }^{167}$ The lowest shrinkage of material, as well as best tailored porosity and high surface area can be obtained for supercritically dried gels; however, the process is the most complex and requires high temperature and pressure resistant apparatus. Freeze drying is able to preserve mesoporous material with moderate shrinkage, but still the sophisticated appliance is required. The advantage of ambient drying is far more simple equipment and possibility to carry out process in each laboratory, but porous structure is mostly collapsed. Finally, gels are pyrolized at temperature about $1000^{\circ} \mathrm{C}$ or higher to improve their electrical and thermal conductivity and increase in microporosity due to shrinkage of mesopores ${ }^{168}$ which is accomplished by heteroatom loss and structural ordering.

\section{Coal}

Coal is a reservoir of solar energy stored by prehistoric plants as a result of photosynthesis within their organisms. During complicated biochemical and geological processes for a million years, these plants have been transformed into currently exploited coal resources. ${ }^{169}$ Coal is a typical sedimentary rock, whose matrix is composed of organic matter with some inorganic (mineral) components. ${ }^{170}$ Compounds that are assimilated by plants during their live and acidic products of the carbonating process may react with metal ions in the created deposits producing a so-called biogenic mineral substance (inner) and a syngenetic substance linked with an organic matrix. Another source of mineral substance is the coal deposit formation processes, in which mineral components pass through coal beds. This type of mineral substance, which is not bonded to organic matter, is defined as epigenetic or outer-one that can be removed by physical methods. ${ }^{171}$ The share of inner mineral substance in coal is relatively low and cannot be removed by physical methods. It can, therefore, be said that physicochemical properties, as well as technological properties of coal are mainly based on the organic matrix. The organic matter of coal is composed of several elements, carbon, hydrogen, oxygen and, to a lesser extent, sulfur and nitrogen, with a trace amount of phosphorus. The coalification process can be divided into peat, lignite/brown coal, hard coal and anthracite formation. During this process, a starting material undergoes significant chemical and structural changes. ${ }^{172}$ The first process of coalification is a humification of the organic matter, i.e. peat formation, which is composed of numerous reactions such as dehydrogenation, decarboxylation and demethylation, leading to the formation of aromatic structures. Then metamorphism takes place, which is ascribed to further 
changes caused by pressure and temperature. ${ }^{173,174}$ This leads to formation of materials of various coalification extent. ${ }^{175}$ Chemically, metamorphism is combined with depletion of hydrogen and oxygen in organic matter, which is accompanied by the evolution of gaseous $\left(\mathrm{CO}_{2}, \mathrm{CO}, \mathrm{H}_{2} \mathrm{O}\right)$ products. As a result of metamorphism, the gradual increase in coalification from brown coals, hard coals to anthracites can be observed-the organic matter condenses and orders. Aromatization and graphitization, i.e. 3D ordering of $\mathrm{C}$ atoms and graphite-like lattice formation (degenerated graphite structure), causes an increase in electrical conductivity. ${ }^{176}$ Although crude oil and gas are competitors to coal, it is still the key energetic raw material, widely used in iron and steel manufacturing, as well as cement production industries. Continuously developing technologies of gasification and liquefaction enable conversion of coal into gaseous and liquid fuels. ${ }^{177} \mathrm{Coal}$ is still very important for fuel and chemical industries.

\section{Pitch}

Coal tar pitch is a multi-component mixture predominantly composed of polycyclic aromatic hydrocarbons originating from coal processing. High-temperature (up to $360^{\circ} \mathrm{C}$ ) distillation of coal tar, which is a by-product of the coking process, produces tar oils (45-50 wt.\%) and coal tar pitch (50-55 wt.\%). ${ }^{178}$ Essential components of coal tar pitches are polycyclic hydrocarbons containing 3-6 rings, as well as polycyclic heteroaromatic compounds. ${ }^{179-181}$ At room temperature coal tar pitch is a brittle material with a conchoidal fracture and is from dark brown to black in color. ${ }^{182}$ Hydrocarbons with a high amount of heteroatoms, alkyl substituents and benzene rings influence coal tar pitch reactivity, enhance cross-linking and polymerisation. This effect is intensified at temperatures above $450^{\circ} \mathrm{C}$, when polycondensed aromatic systems with a much bigger molecular mass (mesophase) are produced. ${ }^{183,184}$ The viscosity significantly increases up to material solidification. Progressively ongoing dehydrogenation and structure ordering lead to socalled pitch coke $\left(1000^{\circ} \mathrm{C}\right)$, and finally to graphite (ca. $2500^{\circ} \mathrm{C}$ ). The amount of produced coke depends on carbonization process parameters and pitch reactivity, i.e. competitiveness of polymerization and distillation processes of hydrocarbon components. ${ }^{185,186}$ The percentage yield of solid residue is called coking value. In addition to hotmelt hydrocarbon components, the coal tar pitches contain scattered particles of solid substances of organic and inorganic origin. These are inert substances that are not embedded into the mesophase during carbonization, as they deteriorate mesophase content increase and spatial ordering. A characteristic feature of these compounds is insolubility in simple organic solvents, which effectively solubilize other pitch components. Because of this, the inert content can be simply evaluated by solubilizing material in a boiling quinoline or toluene, and its amount is defined as quinoline insoluble (QI) and toluene insoluble, respectively. ${ }^{187}$ It is suggested that cracking products of tar fumes in space under the roof of coking chamber, as well as solid particles (also mineral particles) withdrawn from the feed, are the main sources of inert substances. ${ }^{188}$ The quinoline insoluble parts, which are nonvolatile, enhance coke output in a coal tar pitch carbonization. Consequently, these are desired in processes where pitch acts as a binding agent in carbon and graphite materials production. In other cases, a high amount of QI parts is assumed to be detrimental. An effective method to decrease pitch QI content is its production from a light coal tar. It is selectively charged in coke plants excluding a main receiver, where the heaviest fractions of raw tar are concentrated. However, to obtain pitch without QI parts, the coal tar is additionally filtered, extracted or hot centrifuged. The coal tar pitch is commonly applied in carbon electrodes manufacturing for aluminum industry, and graphite electrodes for steel arc furnaces. It is also used in production of activated carbon, carbon refractory blast furnace linings and clay targets. ${ }^{189}$

\section{EXPERIMENTAL}

Materials presented in this paper were either synthesized in-house or procured from commercial sources. A synthetic graphite powder was purchased from Acros Organics (labelled as GRAPHITE), while natural flake graphite was obtained from the Kahatagaha-Kolongaha mine in Sri Lanka (GRANAT). The sample of anthracite was received from the Institute for Chemical Processing of Coal, Zabrze, Poland, as a reference trade product for sinterability tests using the Roga RI method (ANTHRA). Two types of activated carbon were used, a gritty activated carbon from the SGL Carbon Group Polska in Racibórz (ACTIVE) and activated carbon from Merck (AKOHLE). Expanded graphite was produced in thermal treatment of graphite oxide: namely, graphite oxidation was performed using the Staudenmaier method, ${ }^{111}$ and then the material was expanded in a tubular furnace purged with inert gas (EXPAND). It allowed desorbing the oxygen containing groups and expanding the material to give a fluffy and light powder. Reduced graphene oxide was produced in oxidation/exfoliation/reduction process-synthetic graphite was oxidized using potassium chlorate in a mixture of concentrated mineral acids for ca $300 \mathrm{~h}$, ultrasonically dispersed in water, and reduced with hydrazine hydrate (RGRO). Vertically aligned multiwalled carbon nanotubes were synthesized in the Department of Materials Science and Metallurgy, Cambridge University, UK, in a chemical vapor deposition process from toluene (Fisher Scientific) as a carbon precursor and ferrocene $(99.5 \%$, Alfa 
Table I. Specific surface area, total pore volume and mean pore diameter obtained for considered materials/ and referenced data from literature

\begin{tabular}{|c|c|c|c|c|c|}
\hline Material & BET $/ \mathrm{m}^{2} / \mathrm{g}$ & $V_{\text {pores }}(17-509 \AA) / \mathrm{cm}^{3} / \mathrm{g}$ & Pore size/nm & $\begin{array}{c}\mathrm{BET} / \mathrm{m}^{2} / \mathrm{g} \\
{[\text { References] }}\end{array}$ & $\begin{array}{r}V_{\text {pores }} / \mathrm{cm}^{3} / \mathrm{g} \\
{[\text { References] }}\end{array}$ \\
\hline GRAPHITE & 10.91 & 0.0245 & 7.86 & $12-17^{41}$ & $0.04^{191}$ \\
\hline GRANAT & 1.03 & 0.0026 & 10.22 & $1.1^{192}$ & - \\
\hline ANTHRA & 0.96 & 0.0016 & 4.97 & $2.2-6.4^{193}$ & $0.03-0.07^{193}$ \\
\hline ACTIVE & 631.31 & 0.2049 & 5.06 & $1400-2200^{194}$ & $0.8-2.6^{195}$ \\
\hline AKOHLE & 1166.02 & 0.2534 & 2.46 & & \\
\hline COKE & 2.78 & 0.0058 & 6.79 & $0.004-0.009^{193}$ & $0.8-1.9^{193}$ \\
\hline EXPAND & 201.72 & 0.6592 & 12.97 & $130^{196}$ & $10-22^{197}$ \\
\hline RGRO & 22.89 & 0.0452 & 8.21 & $248^{198}$ & $1.5^{199}$ \\
\hline CARPET & 44.39 & 0.0828 & 6.68 & $80-220^{200}$ & $0.37^{201}$ \\
\hline NANOCYL & 231.44 & 0.5648 & 10.44 & & \\
\hline FULLER & 0.63 & 0.0006 & 4.12 & $1.1^{202}$ & - \\
\hline CAHTSCD & 581.59 & 0.6973 & 8.12 & $520-1150^{166,203}$ & $0.09-2.5^{204,205}$ \\
\hline CALTSCD & 494.34 & 0.7897 & 16.20 & & \\
\hline CALIO & 723.95 & 0.0197 & 5.12 & & \\
\hline ARTI & 3228.71 & 4.6538 & 4.16 & $5-360^{206}$ & $0.01-0.08^{51}$ \\
\hline WOOD & 50.29 & 0.0033 & 27.23 & & \\
\hline STRAW & 3.66 & 0.0086 & 9.60 & & \\
\hline BROWN & 2.88 & - & - & $8^{207}$ & $0.05^{207}$ \\
\hline PAKZIC & 0.50 & 0.0007 & 4.89 & $0.6^{208}$ & - \\
\hline TERPAKAT & 0.66 & 0.0012 & 6.72 & & \\
\hline GRANPAK & 0.92 & 0.0007 & 3.41 & & \\
\hline
\end{tabular}

Table II. The interlayer distance and crystallite sizes of examined carbon-based materials

\begin{tabular}{|c|c|c|c|c|}
\hline Material & $d_{002} / \mathbf{n m}$ & $L_{\mathbf{C}} / \mathbf{n m}$ & $L_{\mathbf{a}} / \mathbf{n m}$ & $L_{\mathrm{c}} / L_{\mathrm{a}} / \mathbf{n m}$ [References] \\
\hline GRAPHITE & 0.34 & 19 & 39.5 & $20-100 / 37.1^{41,209}$ \\
\hline GRANAT & 0.34 & 24 & 59 & $90-110 /-^{210}$ \\
\hline ANTHRA & 0.37 & 1 & - & $1.36 / 5^{211}$ \\
\hline ACTIVE & 0.38 & 1 & - & $0.84-3.3^{212}$ \\
\hline AKOHLE & - & - & - & \\
\hline COKE & 0.35 & 1.8 & - & $14.5-41 / 23.2-39.7^{213}$ \\
\hline EXPAND & 0.39 & 2.6 & - & $15.4 / 24.1^{214}$ \\
\hline RGRO & 0.34 & 18.2 & 11.1 & $1-6.8 / 7.8-9.7^{209}$ \\
\hline CARPET & 0.34 & 8.2 & 69 & $-/ 3^{215}$ \\
\hline NANOCYL & 0.35 & \multirow{2}{*}{\multicolumn{2}{|c|}{$D=35 \mathrm{~nm}$}} & $1.3-2 / 6.1^{216,217}$ \\
\hline FULLER & 0.04 & & & $D=55^{218}$ \\
\hline CAHTSCD & 0.40 & 0.9 & - & $1.3-27 / 2.7-4^{219,220}$ \\
\hline CALTSCD & 0.34 & 8 & 9.8 & \\
\hline CALIO & - & - & - & \\
\hline ARTI & - & - & - & - \\
\hline WOOD & 0.38 & 1 & - & $-/ 2.1-2.6^{221}$ \\
\hline STRAW & 0.37 & 1 & - & $0.74-0.82 / 1.7-2.3^{222}$ \\
\hline BROWN & - & - & - & $0.71-0.79 / 2-2.1^{223}$ \\
\hline PAKZIC & 0.34 & 2.6 & - & $7.39 / 5.53^{224}$ \\
\hline TERPAKAT & 0.35 & 2.3 & - & \\
\hline GRANPAK & 0.36 & 1.4 & - & \\
\hline
\end{tabular}

Aesar) as a catalyst at $760^{\circ} \mathrm{C}^{190}$ - (CARPET). Another type of carbon nanotube was purchased from Nanocyl SA, Belgium: multiwalled carbon nanotubes NC7000 (NANOCYL). Fullerenes were purchased from Sigma Aldrich (FULLER). Carbon aerogels were synthesized using resorcinol, formaldehyde solution and sodium carbonate as a catalyst. Synthesis was composed of $72 \mathrm{~h}$ mixing, 7 days of aging, solvent exchange and drying. Three different drying techniques were applied, low temperature supercritical drying (LTSCD) with carbon dioxide at $15 \mathrm{MPa}$ and $70^{\circ} \mathrm{C}$, high temperature supercritical drying (HTSCD) at $250^{\circ} \mathrm{C}$ and $6 \mathrm{MPa}$, and freeze-drying (liofilization) in Alpha 1-2 
Table III. TG data presenting residual mass after treatment from ambient up to $1000^{\circ} \mathrm{C}$, and mass losses divided into two steps: ambient $-500^{\circ} \mathrm{C}$, and $500-900^{\circ} \mathrm{C}$

\begin{tabular}{|c|c|c|c|}
\hline Material & Residual mass $/ \%$ & Mass loss $\left(0-500^{\circ} \mathrm{C}\right) / \%$ & Mass loss $\left(500-900^{\circ} \mathrm{C}\right) / \%$ \\
\hline GRAPHITE & 99.11 & 0.23 & 0.46 \\
\hline GRANAT & 99.94 & 0.15 & 0.02 \\
\hline ANTHRA & 93.78 & 2.02 & 3.83 \\
\hline ACTIVE & 91.35 & 3.39 & 4.15 \\
\hline AKOHLE & 89.29 & 3.24 & 6.36 \\
\hline COKE & 99.42 & 0.08 & 0.27 \\
\hline EXPAND & 71.53 & 10.08 & 14.3 \\
\hline RGRO & 43.32 & 45.15 & 8.21 \\
\hline CARPET & 96.67 & 1 & 0.96 \\
\hline NANOCYL & 95.55 & 2.54 & 1.43 \\
\hline FULLER & 8.61 & 0.39 & 90.39 \\
\hline CAHTSCD & 93.88 & 2.13 & 1.91 \\
\hline CALTSCD & 92.87 & 4.87 & 1.58 \\
\hline CALIO & 86.52 & 10.96 & 2.17 \\
\hline ARTI & 86.69 & 6.95 & 5.21 \\
\hline WOOD & 96.58 & 0.89 & 1.97 \\
\hline STRAW & 92.32 & 3.99 & 2.56 \\
\hline BROWN & 52.66 & 37.17 & 11.4 \\
\hline PAKZIC & 76.34 & 19.5 & 3.79 \\
\hline TERPAKAT & 64.16 & 26.73 & 8.78 \\
\hline GRANPAK & 38.43 & 55.42 & 5.89 \\
\hline
\end{tabular}

LDplus, initially at $-43^{\circ} \mathrm{C}$ and pressure 0.1 mbar. Carbon aerogels were then carbonized in a tubular electric furnace at about $900^{\circ} \mathrm{C}$ for $0.5 \mathrm{~h}$ in an inert gas atmosphere. Regarding the drying method, the synthesized carbon aerogels were denoted as CALTSCD (carbon aerogel low temperature supercritical drying), CAHTSCD (carbon aerogel high temperature supercritical drying), CALIO (freezedried carbon aerogel).

Materials subjected to carbonization were commercially purchased as cereal straw pellets (STRAW) used as fuel in PGE power station in Rybnik, wood waste pellets (WOOD) used as fuel in domestic heating ovens and supercritically dried Jerusalem artichoke stems (ARTI). In all cases carbonization trials were carried out in a Jenker's tube at $900^{\circ} \mathrm{C}$, pressure close to ambient, without air supply. Brown coal was supplied by Bełchatów coal mine in Bełchatów, Poland. Mesophase coal tar pitch (PAKZIC) was produced from light coke oven tar in $12 \mathrm{~h}$ thermopreparation at $410^{\circ} \mathrm{C}$ from the installation operating at the Institute for the Chemical Processing of Coal in Zabrze, Poland. Thermally prepared atmospheric pitch (TERPAKAT), known as soft pitch, was produced by atmospheric distillation of coal tar, and the granular pitch (GRANPAK), known as hard pitch, was a residue after vacuum distillation of coal tar, produced in formerly operated Blachownia chemical plant in KędzierzynKoźle, Poland.

\section{Characterization}

Sample morphology was analyzed using a scanning electron microscope (SEM) NOVA NanoSEM
200 (FEI Company, USA) combined with an EDS analyzer (EDAX, USA). Images at magnification $1000 \times$ and $10000 \times$ were obtained for all materials. Nitrogen adsorption isotherms were found using 3Flex (Micromeritics). The specific surface area was calculated using the Brunauer-Emmett-Teller (BET) method. Pore size distribution and their mean values were calculated based on adsorption part of the hysteresis loop using the BarrettJoyner-Halenda (BJH) method). Thermal analysis was performed in nitrogen atmosphere with a temperature increment $10^{\circ} \mathrm{C} / \mathrm{min}$ up to $1000^{\circ} \mathrm{C}$ in corundum cruicibles, using NETZSCH STA 449F3. Two methods were used, thermogravimetric and differential scanning calorimetry. XRD analysis was performed using Co $\mathrm{K} \alpha$ lamp in $2 \theta$ range from $10^{\circ}$ to $100^{\circ}$ (Seifert FPM).

\section{Electrochemical Characterization}

Electrochemical experiments were carried out using a two-electrode symmetric system and Autolab PGSTAT 302/N workstation. The working electrode materials were pasted on electrochemical nickel current collectors, which were separated with a membrane (Whatman) soaked with $6 \mathrm{M} \mathrm{KOH}$. Electrodes, current collectors and separators were pressed by four screws in a poly(methyl methacrylate) casing. Three types of measurements were performed: cyclic voltammetry to establish cycle life of the electrode material (1000 charge/discharge cycles,potential window $0-1 \mathrm{~V}$, scan rate $500 \mathrm{mV} / \mathrm{s}$ ), galvanostatic charge/discharge characteristics (GC) to evaluate the specific capacity of the matrix and composite (various current densities strongly 
Table IV. The specific gravimetric capacity and cyclability test results

\begin{tabular}{lcc}
\hline Material & Cyclability/\% left after 1000 cycles & Specific capacity/F/g \\
\cline { 2 - 3 } GRAPHITE & 66.7 & $0.9-1.2$ \\
GRANAT & 100 & $0.6-1.9$ \\
ANTHRA & 91 & $0.25-0.4$ \\
ACTIVE & 100 & $47-71$ \\
AKOHLE & 73.5 & $80-100$ \\
COKE & 85 & $1-1.25$ \\
EXPAND & 81.3 & $52-54$ \\
RGRO & 99.9 & $60-67$ \\
CARPET & 91.8 & $1.1-2.1$ \\
NANOCYL & 93.6 & $10-14.7$ \\
FULLER & 80 & $0.3-0.8$ \\
CAHTSCD & 74 & $25-42$ \\
CALTSCD & 90.5 & $14-17$ \\
CALIO & 163 & $30-54$ \\
ARTI & 78.7 & $3.3-5$ \\
WOOD & 78 & $2.5-5$ \\
STRAW & 66.1 & $8.4-9.2$ \\
BROWN & 54.5 & $0.24-0.28$ \\
PAKZIC & 100 & $0.15-0.24$ \\
TERPAKAT & 110 & $0.13-0.33$ \\
GRANPAK & 100 & $0.7-1.9$ \\
\hline
\end{tabular}

dependent on material properties), and the electrochemical impedance spectroscopy (EIS) to determine the resistance of the electrode processes (frequency range $100 \mathrm{kHz}-100 \mathrm{mHz}$ with the amplitude of sinusoidal voltage signal equal $10 \mathrm{mV}$ ).

\section{RESULTS}

\section{Morphology}

The great variety of carbon-based materials is reflected in a broad range of their structures, from dense amorphous to stacked ordered. Differences can be found in particles size and shape, as well as in porosity and pore size distribution. By using particular laboratory procedures the carbon-based materials can be tailored to have a desired structure with a proper content of specific pore size. Carbon material precursors and products (produced or mined on a large scale, such as graphites, cokes, coals and pitches) may have significantly different structures from each other. The morphology of such materials was analyzed using scanning electron microscopy, which allowed distinguishing the wellordered regular domains with a repeating units, and more amorphous structures of randomly scattered particles. All materials were analyzed at magnification $10000 \times$, which enables detailed insight into the structure (Fig. 1).

The well-ordered structures were observed for synthetic and natural graphites as expected. Both showed lamellar stacks of graphene layers with very few imperfections. Contrarily to synthetic graphite, the natural graphite revealed significantly more uniform and bigger particle sizes. Athracite resulted in a dense and compact structure with little diversification and lack of noticeable pores and holes. Among two active carbons, one from SGL company labeled as ACTIVE was composed of bigger chunks that were more uniform in shape, while AKOHLE presented relatively bigger amount of smaller particles with irregular shapes (probably resulting from improper production technique). Coke, which visually is thought to be a porous material resulted in the combination of bigger blocks (as a consequence of high temperature treatment) and smaller globular particles responsible for its sponge-like structure. The graphene-like materials, expanded graphite, which in fact is thermally reduced graphite oxide, and the chemically reduced graphene oxide revealed a corrugated graphene layer arrangement. High energy combined with thermal treatment is responsible for fast desorption of the oxygen-containing groups leading to a rose-like structure. For chemically reduced graphene oxide, this effect can be observed to a smaller extent when a strong reducing agent such as hydrazine or metal hydrides, where the desorption of functional groups is much slower, are used. Consequently, the layers, although partially corrugated, are tightly stacked in a more dense material. Multi-walled carbon nanotubes produced in the form of carpet presented an ordered structure with straight nanotubes with a small amount of defects and entanglings. Nanotubes of a commercially purchased NANOCYL were more disordered, the tubes were shorter, mixed or broken and some amount of amorphous carbon was also found. Fullerenes at lower magnification showed spherical bigger particles, which in 
fact were composed of some cuboidal bigger particles surrounded by smaller post-synthesis residues. Carbon aerogel dried in acetone (CAHTSCD) was composed of uniform small particles that were evenly scattered within the sample. Drying in $\mathrm{CO}_{2}$ (CALTSCD) resulted in a very heterogenous, nonuniform structure with some sponge-like particles mixed with tubular nanotube-like structures. A carbon aerogel that was prepared using freezedrying had a consistent and homogenous structure with scarcely visible pores and defects. A carbonized Jerusalem artichoke showed a very intriguing structure. At first glance typical compact chunks were found; however, at bigger magnification it appeared that material was composed of rod-like structures with spherical ornaments hanging on it. These smaller particles were uniform and evenly distributed within the bigger domains. Quite different was the image registered for carbonized wood with relatively ordered compact particles. Some lamellar-like structure of this material can be recognized; however, higher magnification would be required to check this observation. A carbonized straw presented a porous morphology with regular channels and some defragmentation caused probably by carbonization process of this mechanically weak material. The appearance of brown coal was ascribed to low porosity and strongly amorphous structure. All three pitches were quite similar to each other with interesting "crater-like" particles. They were made of circular and regular coins with rugged edges observed for TERPAKAT and relatively amorphous form for pitch from a continuos operation process and granular atmospheric pitch.

\section{Surface Area and Porosity}

Probably the most important parameter that allows carbon materials to be a key product in batteries and capacitors industries is a tailored structure with a high specific surface area and proper porosity. Well-developed surface area produces a bigger electrode-electrolyte double layer, resulting generally in higher specific capacity. As it was emphasized in the introduction, there is no direct relation between specific surface area and specific capacity. Proper pore size distribution, electrical conductivity, hydrophilicity are very important for the resulting performance. Table I presents the BET analysis results. The total volume of pores and the calculated mean pore diameter for analyzed samples is shown. Data were not distinguished for micro-, meso- or macroporosity, as in some cases pore analysis was very complex (low material stability on heating) and results acquisition was time-consuming beyond reasonable extent. Comparatively, data concerning specific surface area and total pore volume for similar materials, which were found in literature, were showed with references in parenthesis.
As it was expected, a high specific surface area was found for activated carbons, carbon aerogels and a selected type of carbonized natural product. Intriguing was the very high surface area of carbonized Jerusalem artichoke, which was in accordance with the peculiar structure of this material as observed by SEM. Although, the total pore volume of the artichoke was significantly bigger with respect to the other materials, the calculated mean pore diameter was relatively small. This may be attributed to presence of micropores and macropores, without a properly developed mesoporosity. Carbonized wood and straw presented very low surface area and high pore diameter that is a consequence of mostly big macroporous channels within the samples as can be predicted based on microscopic images. This showed unequivocally that significant differences may be observed within the same class of materials with respect to the various raw material. Carbon aerogels used in this review were all based on sodium carbonate catalyst in a most typical resorcinol/catalyst ratio. The specific surface area measured for these materials were in the range of several hundreds of $\mathrm{m}^{2} / \mathrm{g}$. Based on SEM images the structure of freeze-dried sample combined some ordered and disordered fragments that induced a balance of high surface area and reasonably high pore volume. However, the mean size of pores was relatively big. Change in catalyst type and substrate ratio may produce tailored bigger surface area carbon gels. Exfoliation of graphite oxide resulted in bigger interlayer distance of graphene layers with smaller flakes of a corrugated structure. The chemical reduction into reduced graphene oxide doubled the surface area, and pore volume as compared with synthetic graphite. On the contrary, when subjected to a quick thermal shock graphene oxide may take a form of a very light material with a significantly developed surface area and total pore volume bigger by one order of magnitude than that of reduced graphene oxide. This is a result of much bigger energy delivered to the sample by thermal shock. The ordered structure of CNT carpets with densely packed tubes produced much smaller specific surface area than commercial NANOCYL sample, which was composed of randomly oriented tubes and some amorphous matter. Fullerenes showed the BET and porosity parameters much close to those of pitches. All these materials were defined by dense and compact structure. This strongly limited their usage in energy storage materials in such a form, i.e. further thermal treatment and activation of pitches is required. Other industrially based materials such as coke and brown coal presented a very low value for energy storage application. In spite of the ordered structure, the imperfection of anthracite and natural graphite requires a further chemical treatment prior to use in the supercapacitors 
industry. Still, as the price and availability of feedstock is of great importance, the industrially produced materials have a great advantage in comparison to laboratory or technical scale production of some novel carbon materials.

\section{Crystallographic Structure}

X-ray powder diffraction was used to calculate the interlayer distance and crystallite size of the analyzed graphitic domains. It should be pointed out that this technique is inappropriate and may induce big errors in amorphous materials analysis. Two types of crystallites size were presented, the dimension in c-axis called the crystallite height $\left(L_{\mathrm{c}}\right)$ and aaxis dimension called lateral size of crystallite $\left(L_{\mathrm{a}}\right)$. Normalized registered patterns are shown in Fig. 2, while the determined structural data in Table II. Synthetic and natural graphite had very high intensity of their signals (separate y axis on the left) in comparison to the rest of materials. This was result of well-ordered crystalline structure with reproducible layer arrangement. The increased intensity of a typical carbon signal around $30^{\circ}$ was found for CARPET (it should be emphasized that typically the graphitic domain manifests as a highintensity signal around $26^{\circ}$; however, in this case the sample was analyzed with a cobalt lamp instead of copper, thus a slight shift toward a bigger angle was observed). A high and relatively narrow signal was registered for chemically reduced graphene oxide too. For the rest of materials a broader and low intensity signals were found, which was due to the amorphous or less-ordered structures.

Based on the obtained patterns the biggest crystallite heights were calculated for graphite, reduced graphene oxide and CNT carpet. Lc parameter was relatively low for other samples. The interesting is the fact that crystallite height calculated for pitches was close to that obtained for expanded graphite. Although the precursor of EXPAND was synthetic graphite the oxidation, exfoliation and thermal treatment tore graphene layers and made them highly corrugated. Consequently, crystallites were diminished to those observed for amorphous pitches. Consistent with expectations the interlayer spacing for RGRO and EXPAND was slightly bigger than for parent graphite (bigger $d_{002}$ and XRD signal shifted to the left). This is a result of structure exfoliation and separation produced by desorbing oxygen species.

Because of the big structure degradation and many imperfections, the lateral size of crystallite was relatively hard to determine for most samples. The graphitic domains in many of the analyzed samples are very small therefore results of interlayer distance determined for active carbons, carbon gels, and pitches should be interpreted with caution. Instead of typical $L_{\mathrm{c}}$ and $L_{\mathrm{a}}$ sizes, the sphere diameter was calculated for fullerenes.

\section{Thermal Analysis}

Thermogravimetric and differential scanning calorimetry were used to characterize thermal stability of examined materials. DSC curves allowed observation of thermal effects accompanying dehydration, degassing and thermal decomposition of samples. A set of TG and DSC curves, separately for individual samples, was presented in a Fig. 3, while calculated data in Table III.

The smallest mass loss was observed for natural and synthetic graphite and coke $(<1 \%)$. The slight exothermic effects can be attributed to residual impurities removal. Removal of ca $3.5 \%$ and ca $4.5 \%$ of the initial mass was registered for two types of carbon nanotubes, namely, CNT carpets and commercial Nanocyl ${ }^{\mathrm{TM}}$, respectively. These values may suggest a similar amount of impurities in both materials; however, the SEM images showed significant differences with a big amount of disorder in NANOCYL. DSC curves were very similar in both cases showing partial decomposition of material. Thermally treated graphite oxide (EXPAND) showed a $30 \%$ mass loss, which can be attributed to desorption of the residual oxygen interlayer functionalities (carboxyl, epoxy and hydroxyl groups) and decomposition of smaller intralamellar heteroatomic packets. A different situation was observed for chemically reduced graphene oxide (RGRO) with most of the oxygen-containing groups removed in the range $80-250^{\circ} \mathrm{C}$ and some residual functionalities, probably of carboxy and hydroxyl origin, desorbing closer to the end of process. As a consequence a sharp exothermic peak was found for desorbing oxygen-containing groups and broader signal for structure ordering in the latter part of the process. The fullerenes showed the biggest mass loss among all analyzed samples with an almost perfect thermal stability up to $600^{\circ} \mathrm{C}$ and quick degradation up to $900^{\circ} \mathrm{C}$. The low intensity DSC signal around $700^{\circ} \mathrm{C}$ can be an artifact due to mechanical shock or pan movement.

Data registered for both activated carbons strongly resembled each other, with mass losses around $10 \%$ caused by removal of surface-bound functional groups and thermal effects combined with structure rearrangement during annealing. Although, anthracite is theoretically a carbon form of the highest carbon content, about $6 \%$ mass loss was observed for it. The shape of the calorimetric curve indicated more reordering of the structure rather than material degradation. Carbon aerogels presented mass losses in the range of 5.5-13\%. The biggest value of mass loss was observed for the freeze-dried sample (CALIO).

This may indicate that drying organic gels at high T\&p (HTSCD, LTSCD) partially removed surface functionalities, while freeze-drying preserved functional groups within the material. Consequently, during further carbonization most were removed 
from HTSCD and LTSCD during carbonization, but some of the oxygen and nitrogen species were still present in CALIO. As expected, the smallest heat flow was observed for high temperature supercritically dried material with an exothermic signal attributed to cross-linking. In CALTSCD an additional decomposition signal was found. Differences in mass losses with respect to the various feedstock were revealed for carbonized materials. The smallest mass loss was observed for wood-based material with about $1 \%$ difference at $500^{\circ} \mathrm{C}$ with a stronger exothermic signal followed by the small endothermic at the highest temperature. The artichoke showed two evenly distributed steps with $6 \%$ mass loss that based on DSC analysis can be attributed to decomposition reaction. The thermal effect of cereal straw was distributed between two interfering exothermic signals around $500-800^{\circ} \mathrm{C}$ and a small endothermic signal at the end of the process. PAKZIC and GRANPAK showed very similar shape of TG and DSC curves; however, the mass loss of the latter was twice as high as for PAKZIC. Most of the mass was lost in the region of $100-500^{\circ} \mathrm{C}$ and can be assigned to removal of low-volatile fractions. Consequently, exothermic decomposition signals can be found in the DSC curve with an endothemic valley caused by melting. A very even mass loss was found in TERPAKAT, but the temperature regime was increased to $200-500^{\circ} \mathrm{C}$ in this case. Probably this is a result of thermal pretreatment of this material, which removed lower boiling constituents.

\section{Electrochemical Measurements}

Three types of electrochemical analyses were performed to evaluate usefulness of the examined materials as electrodes for supercapacitors. The most reliable results can be obtained from cyclic voltammetry, galvanostatic charge/discharge and electrochemical impedance spectroscopy. The cyclic voltammetry was used to determine the specific capacity loss in 1000 charge/discharge cycles (Fig. 4). Electrodes were swept with a potential at a scan rate $500 \mathrm{mV} / \mathrm{s}$ in a potential window $0-1 \mathrm{~V}$. Narrow range of accessible potential was imposed by water decomposition potential $(1.23 \mathrm{~V})$. The rectangular shape of CV curves is preferred as it indicates pure non-Faradaic storage mechanism based on double layer formation. Any additional signals and curve rounding may be attributed to chemical reaction of electrolyte and electrode. Two main factors influencing specific capacity is process reversibility and the box-like shape of charge and discharge curve. Important also is a current intensity accompanying these processes, because even if the proper symmetric shape was obtained for some materials, the registered current intensity was incomparably small. The best characteristics were accomplished by ACTIVE, EXPAND, RGRO, NANOCYL, as well as CAHTSCD and CALTSCD. Slightly lower currents (still of the same order), but with symmetric curves were obtained for carbonized straw and artichoke. The specific data of the capacity loss was presented in Table IV.

The high specific capacity of carbon materials is a result of big double layer interphase formation. However, the penetration of pores interior by electrolyte solution requires a proper pore size distribution too. Generally, a decrease in pore size to the size of electrolyte ions strongly enhances the specific capacity. The large specific surface area may be achieved by developed microporosity; however, too small pores may not be penetrated by the electrolyte. An important factor affecting electrolyte penetration within the pores is material wettability. Any additional active sites composed, for example, of oxygen atoms may improve wetting pores and consequently increase the extent of double layer formation. Additionally, these active sites may react with the electrolyte producing a further increase in the specific capacity. On the contrary, an irreversible chemical reaction within carbon materials may deteriorate cycling stability in some cases. For example, freeze-dried gel revealed some amount of functionalities in thermal analysis, but these resulted in an irreversible processes during electrolyte ions transport, while much more oxygen species were still embedded in RGRO and its CV characteristics were better. This is because of the localization of the functional groups and their adjacent atoms. In CALIO, oxygen species are localized within the material, being a part of gel with carbon atoms as neighbours. During electrolyte penetration, these atoms irreversibly react with electrolyte ions and do not return these ions back during discharge. On the contrary, the oxygen functionalities in RGRO are bonded to the graphene layers by single or double carbon-oxygen bonds, which leads to significantly lower capacity loss. The effect of improper pore size may be observed with respect to carbonized Jerusalem artichoke, which presented a large surface area, but developed a microporosity strongly limiting its capacitive behavior. A good compatibility of big surface area and proper pore dimensions was found for activated carbons, reduced graphene oxide, expanded graphite and carbon aerogels, which translated into a high specific capacity. The size of pores has to be tailored regarding final product requirements. As the materials composed mostly of micropores may be applied in high energy density materials, where long discharge is required, mesoporous carbons are more appropriate for high power density application to obtain big "energy injection" in a short time. Based on the current intensity observed in cyclic voltammetry analysis, the resulting specific capacity may be evaluated. For example graphite, anthracite and pitches showed relatively reversible CV curves; however, the current intensity of charge and discharge was two orders of magnitude lower than registered for active carbon and expanded graphite. The most important parameter retrieved 
from CV analysis is process reversibility and capacity loss, but it should be depicted that CV plots may give some additional information regarding materials quality.

The galvanostatic charge/discharge is the most credible technique to evaluate the specific capacity of the supercapacitor. The key features of the ideally polarizable electrodes are symmetric triangular charge/discharge curves, close to zero iR drop (observed in the initial part of discharge, which refers to the potential induced by the resistance of supercapacitor's components), and reproducible results. Curves presented in Fig. 5 were registered at two current densities just to show performance change in a short charge/discharge cycle and in an extended time. In some cases additional current density was examined. The symmetric characteristics were found for ACTIVE, AKOHLE, GRAPHITE, RGRO, NANOCYL, and for CAHTSCD/CALTSCD. It showed that materials presenting good CV characteristics resulted in a high specific capacity. In the case of pitches and carbon nanotubes the specific capacity was lower than expected (Table IV). Therefore, often to reach the best performance carbon nanotubes must be intercalated either by conductive polymers or metal oxides prior to use as electrodes.

Graphite as the one of the most popular electrode materials, showed low specific capacity value with an average cyclability. But it must be mentioned that graphites are mainly used in lithium-ion battery production rather than supercapacitors because of their high affinity to store lithium atoms. Slightly better results were obtained for carbonized natural precursors. These values are still far from the ideal case. Additionally, graphite can be used asis while carbonized materials need energy consuming thermal treatment. Promising results (in comparison to graphite) were found for coke. This is quite interesting as coke is industrially produced worldwide in big amounts.

The third useful technique for electrode materials evaluation is the electrochemical impedance spectroscopy. Results of this analysis can be presented in the form of a Nyquist plot combining real versus imaginary impedance component (Fig. 6). It allows determination of electrolyte resistance $R_{S}$, charge transfer resistance $R_{\mathrm{CT}}$ and generally the capacitive behaviour of the analyzed material. Two regions can be distinguished in a Nyquist plot, the semicircle corresponding to the Faradaic charge-transfer resistance and a straight line in the low-frequency region representing the ion diffusion in the electrode structure. For an ideal supercapacitor the curve in the low frequency region should be parallel to the $y$ axis, but for a real capacitor it is assumed that the steeper it is the better for electrode characteristic. A semicircle, typical for Faradaic processes, was found for activated carbons, expanded graphite, reduced graphene oxide, commercial carbon nanotubes and freeze-dried carbon gel. In the case of ACTIVE,
RGRO, NANOCYL and CALIO the charge transfer resistance was as high as $0.37 \Omega, 1.19 \Omega, 0.79 \Omega$, and $0.30 \Omega$, respectively. Much bigger values were registered for AKOHLE and EXPAND, namely $37 \Omega$ and $5.9 \Omega$, respectively. The presence of a semicircle is attributed to redox reactions caused by either some intercalations or residual functional groups, which can be present in activated carbon, thermally reduced graphite oxide or chemically reduced graphene oxide. Carboxyl, hydroxyl and epoxy groups are those most commonly found in oxidatively pre-treated carbon materials. On the other hand high material resistance was revealed for brown coal (1100 $\Omega$ ), pitches (600-900 $\Omega$ ), fullerenes $(800 \Omega)$, anthracite $(700 \Omega)$ and to a lesser extent for CNT carpet, coke and natural graphite $(\sim 500 \Omega)$.

As it was emphasized, the specific surface area is one of the key parameters in materials selection for energy storage applications; however, a simple rule "the higher specific surface area the bigger capacity" is not obeyed. Pitches have much smaller specific surface area in comparison to carbon gels (three orders of magnitude), while the difference in specific capacity is of two orders of magnitude only. Similarly, the biggest specific surface area was calculated for artichoke, but its electrochemical properties were rather poor.

The electrochemical tests showed that promising novel materials such as carbon gels or carbonized carbon precursors, with a high specific surface area, may not be perfectly suited for energy storage materials, mostly because of inappropriate pore structure (clogged pores and/or too big micro or nanoporosity inadequate for electrolyte ions diffusion), but the electrical conductivity (caused by carbon structure order and presence of functional groups) may play a role too. The ordered and dense structure of synthetic and natural graphite, as well as anthracite does not allow for gaining proper ion diffusion and consequently high specific capacity. On the other hand, the electrical conductivity of graphite makes it a promising candidate for use in energy storage. Porous carbons with more or less amorphous structure offer high surface area, proper pore distribution, and additional pseudo-capacitive effects; therefore, activated carbons, thermally and chemically reduced graphite oxides have a potential in energy storage materials. It is important to mention that these materials can be simply produced on a big scale. More sophisticated carbon family members have some drawbacks like limited electric conductivity, so additional doping is required to enhance their properties. It was also found that imperfections in commercial carbon nanotube structures positively influenced the specific capacity, mainly regarding proper electrolyte transport. Carbon gels, produced from organic precursors, using different drying techniques, as well as carbonized materials produced from natural precursors (fruits, plants), should be additionally activated prior to use. It is indisputable that the 
morphology and structure of carbon materials can be easily tailored for final applications. The "industrial" materials such as pitches, brown coal or coke are of less importance at present due to low their technology readiness level for this purpose, but after chemical or physical activation their importance may rapidly grow. Despite its porous structure, coke revealed relatively poor capacitive behaviour. Pitch is a very important material in electrode manufacturing, but rather as a feedstock, not as the final material.

\section{CONCLUSIONS}

Diversity of carbon-based materials results in a wide range of tailored products that can be used in different branches of the industry. The goal of this review was to compare this vast family regarding energy storage applications in carbon-based symmetric aqueous electrolyte supercapacitors. Firstly, microscopic analysis showed structural differences in those materials. It was found that morphology of carbonized Jerusalem artichoke was significantly different than expected. Additionally, the type of natural precursor may have a tremendous influence on the product appearance (carbonized straw versus artichoke). Similarly, carbon nanotubes and expanded graphite also show peculiar structures. Appearance of freeze-dried carbon aerogel showed a block-like structure, which considering its high specific surface area, may be attributed to the large extent of microporosity. Combination of specific surface area analysis with electrochemical tests demonstrated that the very high surface area material may suffer froom a relatively low specific capacity. The biggest specific surface area was found for activated carbons, carbon gels and selected carbonized material. On the other hand, the structure of pitches and anthracite was very compact and dense. A proper pore size distribution and total porosity are very important too. Difference in total pore volume between different members of carbon family may exceed two orders of magnitude. The key point is to produce material with a proper pore size distribution, containing big electrolyte arteries and meso-channels distributing electrolyte ions further to micropores. The well-ordered structures were found for graphites, reduced graphene oxide and CNT carpets, with the biggest crystallite sizes. This parameter may be confusing as the highly ordered materials are composed of large plains of graphene layers and the penetration of interlayer space by electrolyte ions may be limited and disrupted. Thermogravimetric analysis and differential scanning calorimetry showed that the biggest thermal stability was observed for graphites and coke (less than $1 \%$ decomposed), while the biggest mass loss was recorded for fullerene, reduced graphene oxide, pitch and brown coal. Tightly stacked ordered graphene layers with low amount of imperfection are thermodynamically stable and can withstand high temperature. On the contrary reduced graphene oxide still has oxygen-bearing functional groups, fullerenes have some carbon imperfections, while pitches and brown coal have a lot of low-boiling substances, which are susceptible to desorption.

Electrochemical performance enabled to distinguish activated carbons, expanded graphite and reduced graphite oxide as notably promising energy storage materials with a high specific capacity, long cycle life and reduced resistance of electrode processes. Presented results, in no circumstances, must not be treated literally. The characteristics of all analyzed materials can be enhanced to some extent by a chemical or physical activation, metal/polymer doping or thermal treatment, which can drastically change their potential for application in the future. In this review, the as-prepared materials were used to understand the capabilities of these materials in their parent state.

\section{ACKNOWLEDGMENTS}

The authors would particularly like to thank Dr. Krzysztof Koziol from Department of Materials Science and Metallurgy, Cambridge University, UK for giving opportunity to synthesize CNTs. Recognition is also due to MSc Elżbieta Szatkowska for her laboratory help in carbon aerogels synthesis. Authors would like to thank Institute of Non-Ferrous Metals for the ability to prepare this paper with particular thanks due to Andrzej Chmielarz and Katarzyna Leszczyńska-Sejda. Authors deeply appreciate contribution of MSc Katarzyna Bilewska in evaluation of $\mathrm{x}$-ray powder diffraction results. Authors would also like to thank National Science Center, Poland (under the Polonez program, Grant Agreement UMO-2015/19/P/ST5/03799) and the European Union's Horizon 2020 research and innovation programme (Marie Skłodowska-Curie Grant Agreement 665778). Authors would also like to acknowledge Foundation for Polish Science for START scholarship (START 025.2017), the Ministry for Science and Higher Education for the scholarship for outstanding young scientists (0388/E-367/ STYP/12/2017) and the Rector of the Silesian University of Technology in Gliwice for the ProQuality Grant (04/020/RGJ18/0057).

\section{OPEN ACCESS}

This article is distributed under the terms of the Creative Commons Attribution 4.0 International License (http://creativecommons.org/licenses/by/4.0/), which permits unrestricted use, distribution, and reproduction in any medium, provided you give appropriate credit to the original author(s) and the source, provide a link to the Creative Commons license, and indicate if changes were made.

\section{REFERENCES}

1. S.E. Chang, T.L. McDaniels, J. Mikawoz, and K. Peterson, Nat. Hazards 41, 337 (2007). 
2. P. Hines, J. Apt, and S. Talukdar, Energy Policy 37, 5249 (2009).

3. P. Kurzweil, A. Hildebrand, and M. Weiß, ChemElectroChem 2, 150 (2015).

4. S. Ducharme, ACS Nano 3, 2447 (2009).

5. P. Sharma and T.S. Bhatti, Energy Convers. Manag. 51, 2901 (2010).

6. H.I. Becker, Patent US2800616A, by General Electric Company (1957).

7. R.A. Rightmire, Patent US3288641A, by Standard Oil Co (1962).

8. J.W. Sprague, Patent US3615829A, by Standard Oil Co (1965).

9. M. Endo, T. Takeda, Y.J. Kim, K. Koshiba, and K. Ishii, Carbon Lett. 1, 117 (2001)

10. M. Hosokawa, K. Sanada, and T. Kawamura, Patent US4313084A, by NEC Corp (1978).

11. V. Augustyn, P. Simon, and B. Dunn, Energ. Environ. Sci. 7, 1597 (2014).

12. N. Choudhary, C. Li, J. Moore, N. Nagaiah, L. Zhai, Y. Jung, and J. Thomas, Adv. Mater. 29, 1605336 (2017).

13. H.L.F. von Helmholtz, Ann. Phys. Berl. 243, 337 (1879).

14. F. Beguin, V. Presser, A. Balducci, and E. Frackowiak, Adv. Mater. 26, 2219 (2014).

15. M. Gouy, J. Phys. Théor. Appl. 9, 457 (1910).

16. D.L. Chapman, Philos. Mag. 25, 457 (1913).

17. O. Stern, Z. Elektrochem. Angew. Phys. Chem. 30, 508 (1924).

18. A. Gonzalez, E. Goikolea, J.A. Barrena, and R. Mysyk, Renew. Sust. Energ. Rev. 58, 1189 (2016).

19. B. Kastening and S. Spinzig, J. Electroanal. Chem. 214 295 (1986).

20. A.C. Forse, C. Merlet, J.M. Griffin, and C.P. Grey, J. Am. Chem. Soc. 138, 5731 (2016).

21. F. Wang, X. Wu, X. Yuan, Z. Liu, Y. Zhang, L. Fu, Y. Zhu, Q. Zhou, Y. Wu, and W. Huang, Chem. Soc. Rev. 46, 6816 (2017).

22. V. Musolino, A. Pievatolo, and E. Tironi, Energy 36, 6697 (2011).

23. M. Winter and R.J. Brodd, Chem. Rev. 104, 4245 (2004).

24. Y. Hori, IEEJ Trans. Electr. Electr. 4, 231 (2009).

25. B.K. Deka, A. Hazarika, J. Kim, Y.B. Park, and H.W. Park, Int. J. Energy Res. 41, 1397 (2017).

26. E. Karden, S. Ploumen, B. Fricke, T. Miller, and K. Snyder, J. Power Sources 168, 2 (2007).

27. V.A. Shah, J.A. Joshi, R. Maheshwari, and R. Roy, in Proceedings of the 15th National Power System Conference, IIT Bombay (2008), p. 142.

28. V. Ruiz, C. Blanco, E. Raymundo-Pinero, V. Khomenko, F. Beguin, and R. Santamaria, Electrochim. Acta 52, 4969 (2007).

29. W. Lu, L. Qu, K. Henry, and L. Dai, J. Power Sources 189 , 1270 (2009).

30. R. Lin, P.L. Taberna, S. Fantini, V. Presser, C.R. Perez, F. Malbosc, N.L. Rupesinghe, K.B.K. Teo, Y. Gogotsi, and P. Simon, J. Phys. Chem. Lett. 2, 2396 (2011).

31. R.G. Roggers and K.R. Seddon, Science 302, 792 (2003).

32. C. Portet, M.A. Lillo-Rodenas, A. Linares-Solano, and Y. Gogotsi, Phys. Chem. Chem. Phys. 11, 4943 (2009).

33. L. Eliad, E. Pollak, N. Levy, G. Salitra, A. Soffer, and D. Aurbach, Appl. Phys. A 82, 607 (2006).

34. Y.J. Kim, Y. Horie, S. Ozaki, Y. Matsuzawa, H. Suezaki, C. Kim, N. Miyashita, and M. Endo, Carbon 42, 1491 (2004).

35. V.M. Gun'ko, V.V. Turov, O.P. Kozynchenko, V.G. Nikolaev, S.R. Tennison, S.T. Meikle, E.A. Snezhkova, A.S. Sidorenko, F. Ehrburger-Dolle, I. Morfin, D.O. Klymchuk, and S.V. Mikhalovsky, Adsorption 17, 453 (2011).

36. T. Zhang, J. Lang, L. Liu, L. Liu, H. Li, Y. Gu, X. Yan, and X. Ding, Chin. Chem. Lett. 28, 2212 (2017).

37. L. Jiang, J. Wang, X. Mao, X. Xu, B. Zhang, J. Yang, Y. Wang, J. Zhu, and S. Hou, Carbon 111, 207 (2017).

38. S. Rodrigues, M. Marques, I. Suarez-RuizI, D. Camean, and B.Kwiecinska Flores, Int. J. Coal Geol. 111, 67 (2013).
39. B. Kwiecinska and H.I. Petersen, Int. J. Coal Geol. 57, 99 (2004).

40. P. Beghein, G. Berlioux, B. du Mesnildot, F. Hiltmann, and M. Melin, Nucl. Eng. Des. 251, 146 (2012).

41. M. Wissler, J. Power Sources 156, 142 (2006).

42. W.M. Goldberger, P.R. Carney, R.F. Markel, and F.J. Deutschle, Granular Grahitic Carbon. Petroleum Derived Carbons (Washington: American Chemical Society, 1986), pp. 200-214

43. F.J. Luque, J.M. Huizenga, E. Crespo-Feo, H. Wada, L. Ortega, and J.F. Barrenechea, Miner. Depos. 49, 261 (2014).

44. N. Murdie and I.A.S. Edwards, J. Mater. Sci. 20, 171 (1985).

45. O. Khvostikova, H. Hermann, H. Wendrock, T. Gemming, J. Thomas, and H. Ehrenberg, J. Mater. Sci. 46, 2422 (2011).

46. P.L. Zaleski, D.J. Derwin, and R.J. Girkant, Patent US6287694B1, by Superior Graphite Co (1998).

47. J.W. Patrick and S. Hanson, Pore Structure of Graphite, Coke and Composites, in Handbook of Porous Solids, ed. F. Schuth, K.S.W. Sing, and J. Weitkamp (Weinheim: WileyVCH, 2002), pp. 1900-1922.

48. L. Edwards, JOM 67, 308 (2015).

49. E.I. Andreikov, O.V. Krasnikova, and I.S. Amosova, Coke Chem. 53, 311 (2010).

50. S. Patel, Rev. Environ. Sci. Biotechnol. 11, 365 (2012).

51. M.N. Alaya, B.S. Girgis, and W.E. Mourad, J. Porous Mat. 7, 509 (2000)

52. N. Arena, J. Lee, and R. Clift, J. Clean. Prod. 125, 68 (2016).

53. J. Mort, R. Ziolo, M. Machonkin, D.R. Huffman, and M.I. Fergusson, Chem. Phys. Lett. 186, 284 (1991).

54. C. Wen, J. Li, K. Kitazawa, T. Aida, I. Honma, H. Komiyama, and K. Yamada, Appl. Phys. Lett. 61, 2162 (1992).

55. W. Yang, K.R. Ratinac, S.P. Ringer, P. Thordarson, J.J. Gooding, and F. Braet, Angew. Chem. Ger. Edit. 49, 2114 (2010).

56. W. Ren and H.M. Cheng, Nat. Nanotechnol. 9, 726 (2014).

57. M. Wilk, A. Magdziarz, I. Kalemba, and P. Gara, Renew. Energy 85, 507 (2016)

58. A.C. Pierre, History of aerogels, in Advances in Sol-Gel Derived Materials and Technologies, Aerogels Handbook, ed. M.A. Aegerter, N. Leventis, and M.M. Koebel (New York: Springer, 2011), pp. 3-18.

59. M. Mastragostino, C. Arbizzani, and F. Soavi, J. Power Sources 97-98, 812 (2001).

60. M. Yassine and D. Fabris, Energies 10, 1340 (2017).

61. X.F. Wang, Z. Chang, M. Li, and Y. Wu, Nanocarbon-based materials for asymmetric supercapacitors, in Nanocarbons for Advanced Energy Storage, ed. X. Feng (New York: Wiley, 2015), pp. 379-415.

62. H. Jankowska, A. Swiatkowski, and J. Choma, Active Carbon (Chichester: Ellis Horwood Ltd., 1991), p. 280.

63. R.Ch. Bansal and M. Goyal, Activated Carbon Adsorption (New York: CRC Press, 2005), pp. 1-520.

64. H. Marsh and F.R. Reinoso, Activated Carbon, 1st ed. (Oxford: Elsevier Science, 2006), pp. 1-554.

65. H. Teng, T.S. Yih, and L.Y. Hsu, Carbon 36, 1387 (1998).

66. Y.V. Pokonova, Carbon 34, 411 (1996).

67. Y. Uraki, Y. Tamai, M. Ogawa, S. Gaman, and S. Tokura, BioResources 4, 205 (2009).

68. M.S. Solum, R.J. Pugmire, M. Jagtoyen, and F. Derbyshire, Carbon 33, 1247 (1995).

69. E. Schroöder, K. Thomauske, C. Weber, A. Hornung, and V. Tumiatti, J. Anal. Appl. Pyrol. 79, 106 (2007).

70. N.M. Nor, L.L. Chung, L.K. Teong, and A.R. Mohamed, J. Environ. Chem. Eng. 1, 658 (2013).

71. V. Dodevski, B. Janković, M. Stojmenović, S. Krstić, J. Popović, M.C. Pagnacco, M. Popović, and S. Pašalić, Colloids Surf. A 522, 83 (2017).

72. W. Tang, Y. Zhang, Y. Zhong, T. Shen, X. Wang, X. Xia, and J. Tu, Mater. Res. Bull. 88, 234 (2017). 
73. C. Rodriguez Correa, T. Otto, and A. Kruse, Biomass Bioenergy 97, 53 (2017).

74. P. González-García, Renew. Sustain. Energy Rev. 82, 1393 (2018).

75. A.J. Romero-Anaya, M. Ouzzine, M.A. Lillo-Ródenas, and A. Linares-Solano, Carbon 68, 296 (2014).

76. P. Costa Vilella, J. Alves Lira, D.C.S. Azevedo, M. BastosNeto, and R. Stefanuttia, Ind. Crop. Prod. 109, 134 (2017).

77. X. Zhu, Y. Gao, Q. Yue, Y. Kan, W. Kong, and B. Gao, Ecotoxcol. Environ. Saf. 145, 289 (2017).

78. J. Wang, T.L. Liu, Q.X. Huang, Z.Y. Ma, Y. Chi, and J.H. Yan, Fuel Process. Technol. 162, 13 (2017).

79. A. Jain, R. Balasubramanian, and M.P. Srinivasan, Chem. Eng. J. 283, 789 (2016).

80. H. Laksaci, A. Khelifi, M. Trari, and A. Addoun, J. Clean. Prod. 147, 254 (2017).

81. A.B. Fadhil, A.I. Ahmed, and H.A. Salih, Fuel 187, 435 (2017).

82. S. Uçar, M. Erdem, T. Tay, and S. Karagöz, Appl. Surf. Sci. 255,8890 (2009)

83. H. Sayğıll and F. Güzel, J. Clean. Prod. 113, 995 (2016).

84. J.H. Tay, X.G. Chen, S. Jeyaseelan, and N. Graham, Chemosphere 44, 45 (2001).

85. X. Chen, S. Jeyaseelan, and N. Graham, Waste Manag. 22, 755 (2002).

86. G. Xu, X. Yang, and L. Spinosa, J. Environ. Manag. 151, 221 (2015).

87. A. Gupta and A. Garg, Clean Technol. Environ. 17, 1619 (2015).

88. C. Wu, M. Song, B. Jin, Y. Wu, and Y. Huang, J. Environ. Sci. 25, 405 (2013).

89. E.L.K. Mui, W.H. Cheung, M. Valix, and G. McKay, Microporous Mesoporous Mater. 130, 287 (2010).

90. P. Hadi, K.Y. Yeung, J. Guo, H. Wang, and G. McKay, J. Environ. Manag. 170, 1 (2016).

91. A.S. Al-Rahbi and P.T. Williams, Waste Manag. 49, 188 (2016).

92. W.K. Lafi, Biomass Bioenergy 20, 57 (2001).

93. G. San Miguel, G.D. Fowler, and C.J. Sollars, Carbon 41, 1009 (2003).

94. N.A. Rashidi and S. Yusup, Chem. Eng. J. 314, 277 (2017).

95. X.F. Tan, S.B. Liu, Y.G. Liu, Y.L. Gu, G.M. Zeng, X.J. Hu, X. Wang, S.H. Liu, and L.H. Jiang, Bioresour. Technol. 227, 359 (2017).

96. F. Rodriguez-Reinoso, M. Molina-Sabio, and M.T. Gonzalez, Carbon 33, 15 (1995).

97. M. Molina-Sabio, F. Rodriguez-Reinoso, F. Caturla, and M.J. Sellés, Carbon 34, 457 (1996).

98. D.H. Everett, Pure Appl. Chem. 31, 577 (1972).

99. Q. Wang, X. Zhu, Y. Liu, Y. Fang, X. Zhou, and J. Bao, Carbon 127, 658 (2018).

100. M.A. Adekunle and N.A. Farid, Renew. Sustain. Energy Rev. 52, 1282 (2015).

101. A. Volperts, G. Dobele, A. Zhurinsh, D. Vervikishko, E. Shkolnikov, and J. Ozolinsh, New Carbon Mater. 32, 319 (2017).

102. N. Guo, M. Li, X. Sun, F. Wang, and R. Yang, Mater. Chem. Phys. 201, 399 (2017).

103. W. Li, Y. Ding, W. Zhang, Y. Shu, L. Zhang, F. Yang, and Y. Shen, J. Taiwan Inst. Chem. Eng. 64, 166 (2016).

104. L.D. Landau, Phys. Z. Sowjetunion 11, 26 (1937).

105. R. Peierls, Ann. Inst. Henri Poincaré 5, 177 (1935).

106. P.R. Wallace, Phys. Rev. 71, 622 (1947).

107. H.P. Boehm, A. Clauss, G.O. Fischer, and U. Hofamnn, Z. Naturforsch. B 17b, 150 (1962).

108. K.S. Novoselov, A.K. Geim, S.V. Morozov, D. Jiang, Y. Zhang, S.V. Dubonos, I.V. Grigorieva, and A.A. Firsov, Science 306, 666 (2004).

109. U. Khan, A. O'Neill, M. Lotya, S. De, and J.N. Coleman, Small 6, 864 (2010).

110. B.C. Brodie, On the atomic weight of graphite. Philos. Trans. R. Soc. 149, 249 (1859).

111. L. Staudenmaier, Ber. Dtsch. Chem. Ges. 31, 1481 (1898).
112. W.S. Hummers Jr and R.E. Offeman, J. Am. Chem. Soc. 80, 1339 (1958).

113. H. He, T. Riedl, A. Lerf, and J. Klinowski, J. Phys. Chem. 100, 19954 (1996).

114. S. Stankovich, D.A. Dikin, R.D. Piner, K.A. Kohlhaas, A. Kleinhammes, Y. Jia, Y. Wu, S.B.T. Nguyen, and R.S. Ruoff, Carbon 45, 1558 (2007).

115. Y. Si and E.T. Samulski, Nano Lett. 8, 1679 (2008).

116. X. Mei and J. Ouyang, Carbon 49, 5389 (2011).

117. M.J. Fernández-Merino, L. Guardia, J.I. Paredes, S. VillarRodil, P. Solís-Fernández, A. Martínez-Alonso, and J.M.D. Tascón, J. Phys. Chem. C 114, 6426 (2010).

118. S. Pei and H.-M. Cheng, Carbon 50, 3210 (2012).

119. L.J. Cote, R. Cruz-Silva, and J. Huang, J. Am. Chem. Soc. 131, 11027 (2009)

120. P.V. Kamat, Chem. Rev. 93, 267 (1993).

121. C. Berger, Z. Song, T. Li, X. Li, A.Y. Ogbazghi, R. Feng, Z. Dai, A.N. Marchenkov, E.H. Conrad, P.N. First, and W.A. de Heer, J. Phys. Chem. B 108, 19912 (2004).

122. W. Strupiński, K. Grodecki, A. Wysmolek, R. Stępniewski, T. Szkopek, P.E. Gaskell, A. Gruneis, D. Haberer, R. Bożek, J. Krupka, and J.M. Baranowski, Nano Lett. 11, 1786 (2011).

123. K.S. Kim, Y. Zhao, H. Jang, S.Y. Lee, J.M. Kim, K.S. Kim, J.-H. Ahn, P. Kim, J.-Y. Choi, and B.H. Hong, Nature 457, 706 (2009)

124. M. Pumera, Chem. Rec. 9, 211 (2009).

125. G. Liang, N. Neophytou, M.S. Lundstrom, and D.E. Nikonov, J. Appl. Phys. 102, 054307-1 (2007).

126. X. Wang, L. Zhi, and K. Müllen, Nano Lett. 8, 323 (2008).

127. D.S. Su, N. Maksimova, J.J. Delgado, N. Keller, G. Mestl, M.J. Ledoux, and R. Schlögl, Catal. Today 102-103, 110 (2005).

128. L.V. Radushkevich and V.M. Lukyanovich, Z. Fiz. Khim. 26, 88 (1952).

129. S. Iijima, Nature 354, 56 (1991).

130. S. Hong and S. Myung, Nat. Nanotechnol. 2, 207 (2007).

131. G.J. Brady, A.J. Way, N.S. Safron, H.T. Evensen, P. Gopalan, and M.S. Arnold, Sci. Adv. 2, 1 (2016).

132. E. Pop, D. Mann, Q. Wang, K. Goodson, and H. Dai, Nano Lett. 6, 96 (2006).

133. D. Janas, A. Cabrero-Vilatela, J. Bulmer, L. Kurzepa, and K.K. Koziol, Carbon 64, 305 (2013).

134. D. Janas, K.Z. Milowska, P.D. Bristowe, and K.K.K. Koziol, Nanoscale 9, 3212 (2017).

135. A. Lekawa-Raus, L. Kurzepa, X. Peng, and K. Koziol, Carbon 68, 597 (2014).

136. D. Janas, A.C. Vilatela, and K.K.K. Koziol, Carbon 62, 438 (2013).

137. K.K. Koziol, D. Janas, E. Brown, and L. Hao, Physica E 88, 104 (2017).

138. A. Lekawa-Raus, T. Gizewski, J. Patmore, L. Kurzepa, and K.K. Koziol, Scr. Mater. 131, 112 (2017).

139. M.-F. Yu, O. Lourie, M.J. Dyer, K. Moloni, T.F. Kelly, and R.S. Ruoff, Science 287, 637 (2000).

140. J.N. Coleman, U. Khan, W.J. Blau, and Y.K. Gun'ko, Carbon 44, 1624 (2006).

141. E.T. Thostenson, Z. Ren, and T.-W. Chou, Compos. Sci. Technol. 61, 1899 (2001).

142. A. Katunin, K. Krukiewicz, R. Turczyn, P. Sul, A. Lasica, and M. Bilewicz, Compos. Struct. 159, 773 (2017).

143. D. Janas, N. Czechowski, B. Krajnik, S. Mackowski, and K.K. Koziol, Appl. Phys. Lett. 102, 181104 (2013).

144. D. Janas, N. Czechowski, S. Mackowski, and K.K. Koziol, Appl. Phys. Lett. 104, 261107 (2014).

145. M.F.L. De Volder, S.H. Tawfick, R.H. Baughman, and A.J. Hart, Science 339, 535 (2013).

146. H.W. Kroto, J.R. Heath, S.C. O'Brien, R.F. Curl, and R.E. Smalley, Nature 318, 162 (1985).

147. J.C. Barnes, E.J. Dale, A. Prokofjevs, A. Narayanan, I.C. Gibbs-Hall, M. Juríček, C.L. Stern, A.A. Sarjeant, Y.Y. Botros, S.I. Stupp, and J.F. Stoddart, J. Am. Chem. Soc. 137, 2392 (2015). 
148. R.C. Haddon, A.F. Hebard, M.J. Rosseinsky, D.W. Murphy, S.J. Duclos, K.B. Lyons, B. Miller, J.M. Rosamilia, R.M Fleming, A.R. Kortan, S.H. Glarum, A.V. Makhija, A.J. Muller, R.H. Eick, S.M. Zahurak, R. Tycko, G. Dabbagh, and F.A. Thiel, Nature 350, 320 (1991).

149. T.R. Ohno, G.H. Kroll, J.H. Weaver, L.P.F. Chibante, and R.E. Smalley, Nature 355, 401 (1992).

150. A.P. Ramirez, Physica C 514, 166 (2015).

151. C.B. Winkelmann, N. Roch, W. Wernsdorfer, V. Bouchiat, and F. Balestro, Nat. Phys. 5, 876 (2009).

152. A.F. Hebard, M.J. Rosseinsky, R.C. Haddon, D.W. Murphy, S.H. Glarum, T.T.M. Palstra, A.P. Ramirez, and A.R. Kortan, Nature 350, 600 (1991).

153. Y. Zhao, Y.-H. Kim, A.C. Dillon, M.J. Heben, and S.B. Zhang, Phys. Rev. Lett. 94, 155504 (2005).

154. Y. Ling, G.K. Koyanagi, D. Caraiman, V. Baranov, and D.K. Bohme, Int. J. Mass Spectrom. 182, 349 (1999).

155. T. Benn, P. Herckes, and P. Westerhoff, Analysis and Risk of Nanomaterials in Environmental and Food Samples, ed. M. Farre and D. Barcelo (Elsevier BV, 2012), pp. 291-301.

156. S.S. Kistler, Nature 127, 74 (1931).

157. R.W. Pekala, J. Mater. Sci. 24, 3221 (1989).

158. S. Mulik and C. Sotiriou-Leventis, in Aerogels Handbook. Advances.Sol-Gel Derived Materials and Technologies, ed. M.A. Aegerter, N. Leventis, and M.M. Koebel (New York: Springer, 2011), pp. 215-234.

159. C. Lin and J.A. Ritter, Carbon 35, 1271 (1997).

160. J. Wang, M. Glora, R. Petricevic, R. Salinger, H. Pröbtle, and J. Fricke, J. Porous Mat. 8, 159 (2001).

161. N. Job, R. Pirard, J. Marien, and J. Pirard, Carbon 42, 619 (2004).

162. M.L. Rojas-Cervantes, J. Mater. Sci. 50, 1017 (2015).

163. M. Wiener, G. Reichenauer, T. Scherb, and J. Fricke, J. Non-Cryst. Solids 350, 126 (2004).

164. S.J. Kim, S.W. Hwang, and S.H. Hyun, J. Mater. Sci. 40, 725 (2005)

165. M.J. van Bommel and A.B. de Haan, J. Mater. Sci. 29, 943 (1994).

166. C. Liang, G. Sha, and S. Guo, J. Non-Cryst. Solids 271, 167 (2000).

167. H. Tamon, H. Ishizaka, T. Yamamoto, and T. Suzuki, Carbon 37, 2049 (1999).

168. A.M. ElKhatat and S.A. Al-Muhtaseb, Adv. Mater. 23, 2887 (2011).

169. D.W. Krevelen, Coal Typology-Physics-Chemistry-Constitution, 3rd ed. (Amsterdam: Elsevier, 1993).

170. J.G. Speight, Handbook of coal analysis (New York: Wiley, 2005), pp. 1-365.

171. H.H. Damberger, The Science and Technology of Coal and Coal Utilization, ed. B. Cooper (New York: Springer, 1984), p. 7.

172. M.A. Rashid, Geochemistry of Marine Humic Compounds (New York: Springer, 1985), pp. 188-211.

173. B.P. Tissot and D.H. Welte, Petroleum Formation and Occurrence, a New Approach to Oil and Gas Exploration (Berlin: Springer, 1984), pp. 3-13.

174. J. Xu, J. Wu, and Y. He, Functions of Natural Organic Matter in Changing Environment (Dordrecht: Springer, 2013), pp. 1-268.

175. C.F.K. Diessel, Coal-Bearing Depositional Systems (Berlin: Springer, 1992), pp. 41-88.

176. M. Teichmüller and R. Teichmüller, Int. J. Earth Sci. 91, $75(2002)$

177. S. Tengler, Wspołczesne metody chemicznej przeróbki wegla (Warszawa: PWN, 1981).

178. D.D. Edie, Pitch and Mesophase Fibers, Carbon Fibers Filaments and Composites (Dordrecht: Kluwer Academic Publishers, 1990), pp. 43-72.

179. M.F. Yardim, E. Ekinci, and K.D. Bartle, Design and Control of Structure of Advanced Carbon Materials for Enhanced Performance (Dordrecht: Kluwer Academic Publishers, 2001), pp. 125-134.

180. M. Zander, Fuel 66, 1536 (1987)
181. P. Fisher, J.W. Stadelhofer, and M. Zander, Fuel 57, 345 (1978).

182. Z. Weishauptova, J. Medek, and Z. Vaverkova, Carbon 32, 311 (1994).

183. J. Machnikowski, H. Machnikowska, T. Brzozowska, and J. Zieliński, J. Anal. Appl. Pyrol. 65, 147 (2002).

184. P.N. Kuznetsov, L.I. Kuznetsova, F.A. Buryukin, E.N. Marakushina, and V.K. Frizorger, Solid Fuel Chem. 49, 213 (2015).

185. M. Perez, M. Granda, R. Santamaria, T. Morgan, and R. Menendez, Fuel 83, 1257 (2004).

186. A. Mianowski, S. Błażewicz, and Z. Robak, Carbon 41, 2413 (2003).

187. C. Panaitescu and G. Predeanu, Int. J. Coal Geol. 71, 448 (2007).

188. J.R. Kershaw and K.J.T. Black, Energy Fuel. 7, 420 (1993).

189. G. Collin and B. Bujnowska, Carbon 32, 547 (1994).

190. S.W. Pattinson, K. Prehn, I.A. Kinloch, D. Eder, K.K.K. Koziol, K. Schulte, and A.H. Windle, RSC Adv. 2, 2909 (2012).

191. M.G. Nijkamp, J.E.M.J. Raaymakers, A.J. van Dillen, and K.P. de Jong, Appl. Phys. A 72, 619 (2001).

192. H.M.A. Asghar, S.N. Hussain, H. Sattar, N.W. Brown, and E.P.L. Roberts, Chem. Eng. Commun. 202, 508 (2015).

193. A. Magasinski, G. Furdin, J.F. Mareche, G. Medjahdi, A. Albiniak, E. Broniek, and M. Jasienko-Halat, Fuel Proc. Technol. 79, 259 (2002).

194. X. Meng, Q. Cao, L. Jin, X. Zhang, S. Gong, and P. Li, J. Mater. Sci. 52, 760 (2017).

195. T.M. O'Grady and A.N. Wennerberg, Petroleum-Derived Carbons, ed. J.D. Bacha, J.W. Newman, and J.L. White (Washington: ACS Symposium Series, 1986), pp. 302309.

196. I.M. Afanasov, O.N. Shornikova, I.I. Vlasov, E.V. Kogan, A.N. Seleznew, and V.V. Avdeev, Inorg. Mater. 45, 135 (2009).

197. M. Toyoda, K. Moriya, J. Aizawa, H. Konno, and M. Inagaki, Desalination 128, 205 (2000).

198. E. Miniach, A. Śliwak, A. Moyseowicz, L. Fernandez-Garcia, Z. Gonzalez, M. Granda, R. Menendez, and G. Gryglewicz, Electrochim. Acta 240, 53 (2017).

199. J. Zeng, J. Amici, A.H.A. Monteverde Videla, C. Francia, and S. Bodoardo, J. Solid State Electr. 21, 503 (2017).

200. S.S. Poulsen, P. Jackson, K. Kling, K.B. Knudsen, V. Skaug, Z.O. Kyjovska, B.L. Thomsen, P.A. Clausen, R. Atluri, T. Berthing, S. Bengtson, H. Wolff, K.A. Jensen, H. Wallin, and U. Vogel, Nanotoxicology 10, 1263 (2016).

201. S.Y. Lia and A.N. Kao, Appl. Catal. A Gen. 496, 79 (2015).

202. E. Papirer, E. Brendle, F. Ozil, and H. Balard, Carbon 37, 1265 (1999)

203. J. Shen and D.Y. Guan. Aerogels Handbook, in Preparation and Applications of Carbon Aerogels, ed. M. Aegerter, N. Leventis, and M. Koebel (New York: Springer, 2011), pp. 813-831.

204. A.M. Shariff, D.M. Beshir, M.A. Bustam, and S. Maitra, Trans. Indian Ceram. Soc. 69, 83 (2010).

205. B. Mathieu, S. Blacher, R. Pirard, J.P. Pirard, B. Sahouli, and F. Brouers, J. Non-Cryst. Solids 212, 250 (1997).

206. A. Cyganiuk, O. Gorska, A. Olejniczak, and J.P. Lukaszewicz, J. Anal. Appl. Pyrol. 98, 15 (2012).

207. Y.V. Tamarkina, V.A. Kucherenko, and T.G. Shendrik, Solid Fuel Chem. 49, 91 (2015).

208. Y. Sato, Y. Kikuchi, T. Nakamo, G. Okuno, K. Kobayakawa, T. Kawai, and A. Yokoyama, J. Power Sources 81-82, 182 (1999).

209. A. Romero, M.P. Lavin-Lopez, L. Sanchez-Silva, J.L. Valverde, and A. Paton-Carrero, Mater. Chem. Phys. 203, 284 (2018).

210. T. Ishii, Y. Kaburagi, A. Yoshida, Y. Hishiyama, H. Oka, N. Setoyama, J. Ozaki, and T. Kyotani, Carbon 125, 146 (2017).

211. X. Gong and S. Zhang, J. Anal. Appl. Pyrol. 127, 170 (2017).

212. B.K. Pradhan and N.K. Sandle, Carbon 37, 1323 (1999). 
213. I.V. Moskalev, D.M. Kiselkov, V.N. Strenikov, V.A. Valtsifer, and K.A. Lykova, Coke Chem. 57, 98 (2014).

214. X. Yue, H. Wang, S. Wang, F. Zhang, and R. Zhang, J. Alloy. Compd. 505, 286 (2010).

215. S. Cui, R. Canet, A. Derre, M. Couzi, and P. Delhaes, Carbon 41, 797 (2003).

216. C. Gupta, P.H. Maheshwari, and S.R. Dhakate, Mater. Renew. Sustain. Energy 5, 2 (2016).

217. P. Delhaes, M. Couzi, M. Trinquecoste, J. Dentzer, H. Hamidou, and C. Vix-Guterl, Carbon 44, 3005 (2006).

218. G.L. Baker, A. Gupta, M.L. Clark, B.R. Valenzuela, L.M. Staska, S.J. Harbo, J.T. Pierce, and J.A. Dill, Toxicol. Sci. 10, $122(2008)$.
219. F.J. Maldonado-Hodar, C. Moreno-Castilla, J. Rivera-Utrilla, Y. Hanzawa, and Y. Yamada, Langmuir 16, 4367 (2000).

220. Z.M. Markovic, B.M. Babic, M.D. Dramicanin, I.D. Holclajtner Antunovic, V.B. Pavlovic, D.B. Perusko, and B.M. Todorovic Markovic, Synth. Met. 162, 743 (2012).

221. S.J. Hill, W.J. Grigsby, and P.W. Hall, Biomass Bioenergy 56, 92 (2013).

222. F. Min, M. Zhang, Y. Zhang, Y. Cao, and W.P. Pan, J. Anal. Appl. Pyrol. 92, 250 (2011).

223. H. Takagi, K. Maruyama, N. Yoshizawa, Y. Yamada, and Y. Sato, Fuel 83, 2427 (2004).

224. Y. Li, Y.S. Hu, H. Li, L. Chen, and X. Huang, J. Mater. Chem. A 4, 96 (2016). 